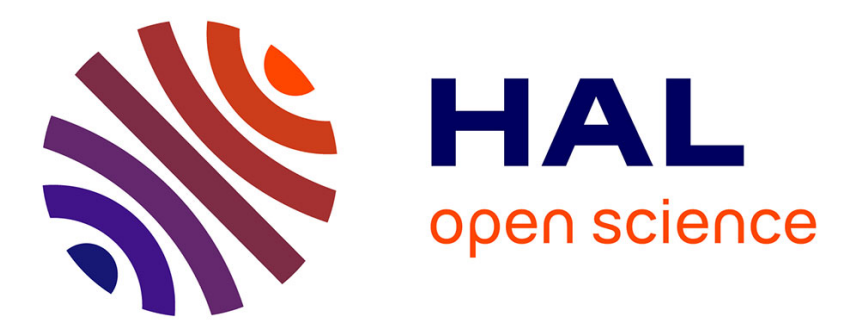

\title{
Global optimization of neutral and charged 20- and 55-atom silver and gold clusters at the DFTB level
}

Nathalie Tarrat, Mathias Rapacioli, Jérôme Cuny, Joseph Morillo, Jean-Louis Heully, Fernand Spiegelman

\section{- To cite this version:}

Nathalie Tarrat, Mathias Rapacioli, Jérôme Cuny, Joseph Morillo, Jean-Louis Heully, et al.. Global optimization of neutral and charged 20- and 55-atom silver and gold clusters at the DFTB level. Computational and Theoretical Chemistry, 2017, 1107, pp.102-114. 10.1016/j.comptc.2017.01.022 . hal-01529346

\section{HAL Id: hal-01529346 \\ https://hal.science/hal-01529346}

Submitted on 29 Jan 2019

HAL is a multi-disciplinary open access archive for the deposit and dissemination of scientific research documents, whether they are published or not. The documents may come from teaching and research institutions in France or abroad, or from public or private research centers.
L'archive ouverte pluridisciplinaire HAL, est destinée au dépôt et à la diffusion de documents scientifiques de niveau recherche, publiés ou non, émanant des établissements d'enseignement et de recherche français ou étrangers, des laboratoires publics ou privés. 


\title{
Global Optimization of Neutral and Charged 20- and 55-Atom Silver and Gold Clusters at the DFTB Level
}

\author{
Nathalie Tarrat ${ }^{\mathrm{a}, *}$, Mathias Rapaciolib ${ }^{\mathrm{b}, *}$, Jérôme Cuny ${ }^{\mathrm{b}}$, Joseph Morillo ${ }^{\mathrm{a}, \mathrm{c}}$, \\ Jean-Louis Heully ${ }^{\mathrm{b}}$, Fernand Spiegelman ${ }^{\mathrm{b}}$ \\ ${ }^{a}$ CEMES-CNRS UPR 8011, 29 rue Jeanne Marvig, BP 94347, 31055 Toulouse Cedex 4, \\ France \\ ${ }^{b}$ Laboratoire de Chimie et Physique Quantiques LCPQ/IRSAMC, UMR5626, Université de \\ Toulouse (UPS) and CNRS, 118 Route de Narbonne, F-31062 Toulouse, France \\ ${ }^{c}$ Université de Toulouse(UPS), 118 Route de Narbonne, F-31062 Toulouse Cedex 9, France
}

\begin{abstract}
The global optimization of metallic clusters is an important topic because nanoclusters exhibit structure-dependent properties. In this paper, we present a global optimization study of $\mathrm{Ag}_{20}, \mathrm{Au}_{20}, \mathrm{Ag}_{55}$ and $\mathrm{Au}_{55}$ in their neutral and charge states $(-1,0,+1)$ conducted using a Parallel-Tempering Molecular Dynamics algorithm at the DFTB level without pre-screening. For $\mathrm{Au}_{20}, \mathrm{Ag}_{20}$ and their ions, the present DFTB low energy structures are in good agreement with previously published calculations and experimental data. In the case of $\mathrm{Ag}_{55}^{-}$and $\mathrm{Au}_{55}^{-}$, the present study is consistent with photo-electron detachment experiments suggesting highly symmetric icosahedral structures for silver and more disordered morphologies for gold. The present results are also compatible with trapped ion electron diffraction experiments and calculations for $\mathrm{Ag}_{55}^{+}$ and $\mathrm{Ag}_{55}^{-}$. We report low-energy isomers of $\mathrm{Au}_{55}$ exhibiting cavities below their external shell. This work quantitatively confirms the relevance of DFTB for structure calculation of noble metal clusters. Furthermore, it also demonstrates the feasibility of global optimization using DFTB, without pre-screening through classical potential, for sizes up to a few tens of atoms and for different charge states.
\end{abstract}

\footnotetext{
${ }^{*}$ Corresponding authors

Email addresses: nathalie.tarrat@cemes.fr (Nathalie Tarrat), mathias.rapacioli@irsamc.ups-tlse.fr (Mathias Rapacioli)
}

Preprint submitted to Computational and Theoretical Chemistry 
Keywords: Gold, Silver, Clusters, Global Optimization, DFTB 


\section{Introduction}

The prediction of the atomic structure of nanoclusters is of fundamental importance as they often exhibit size-dependent properties. A deep knowledge of the structural changes arising as a function of the nanocluster size and charge 5 can lead to the development of materials exhibiting desirable properties. Among nanoclusters, silver and gold ones display very specific optical $[1,2,3,4,5,6,7$, $8,9,10,11,12,13]$ and chemical $[14,15,16,17,18,19,20,21,22]$ properties. A variety of experimental and computational methods have thus been used to predict their structures in their neutral or charged states i.e. $\mathrm{Ag}_{n}^{-, 0,+}$ and $\mathrm{Au}_{n}^{-, 0,+}$

${ }_{10}[23,24,25,26,27,28,29,30,31,32,33,34,35,36,37,38,39,40,41,42,43$, $44,45,46,47,48]$.

Among others, the structure of noble metal clusters has now become a very topical theme with the possibility of monitoring directly their structural behaviors via STEM imaging [49]. For the medium-size silver and gold clusters with 20 and 55 atoms, the presently known structures are issued from either theoretical studies or studies coupling experimental characterization with DFT calculations $[27,28,39,50,51,52,53]$. However, to the best of our knowledge, no full DFT exploration of the potential energy surface (PES) of such clusters is mentioned in the literature. Indeed, despite fast progress in the derivation of accurate functionals and efficient algorithms to be implemented on high performance computers, DFT is not yet efficient enough to be directly used within global and extensive exploration of PES. Consequently, most global explorations in the field of structure prediction of medium-size metallic clusters use pre-screening, i.e. are performed by first exploring the energy landscapes using an empirical or a semi-empirical potential. This is followed by a subsequent optimisation of the lower-energy structures at a higher level of accuracy, generally DFT.

To study such systems with an accuracy close to that of $a b$ initio meth- 
ods, parameterized quantum approaches offer an attractive alternative as they preserve, with some approximations, the electronic description of the system while displaying a significantly lower computational cost. An explicit quantum description of the electronic structure is obviously desirable when one wishes to describe several charge states within a unique scheme, which is almost impossible when using classical force fields. Among the available options, the Density-Functional based Tight-Binding method (DFTB) is considered as a state-of-the-art parameterized method $[54,55,56,57,58,59]$. It is derived from DFT via several approximations and has proved to be particularly efficient for the description of complex molecular systems $[60,61,62,63]$. Its accuracy depends significantly on the quality of the parameterization. In particular, it requires the use of tabulated integrals, referred to as the Slater-Koster integrals, constructed for each atomic pair of the chemical system of interest. These Slater-Koster integrals are not uniquely defined as they can be developed using various methodologies and reference DFT functionals. In the particular case of silver and gold, several DFTB parameter sets have been proposed in the literature $[64,65,66]$. In a recent study [67], we improved such parameters for silver and gold clusters and showed that these modified parameters are satisfactory in reproducing essential differences between small silver and gold clusters. 50 In particular, their 2D-3D structural transition and its dependency upon cluster charge state is well reproduced as well as a variety of bulk properties. Our DFTB results were also in agreement with previously reported DFT and experimental data in the medium-size regime regarding the energetic ordering of the various low-energy isomers already described in the literature. The satisfactory behavior of these parameters regarding the modeling of middle-size silver and gold clusters now provides opportunities to perform global exploration of the PES of such aggregates with an approach providing an explicit electronic structure description.

In the present work, we use a Parallel-Tempering Molecular Dynamics algorithm (PTMD) to explore the PES of $\operatorname{Ag}_{n}^{q}$ and $\mathrm{Au}_{n}^{q}$ with $n=20,55$ and 
$q=-1,0,+1$ computed at the DFTB level. The size regime of a few tens is particularly interesting since it provides a transition between the small size regime, where each atom and charge fluctuation matters, and the nanoparticle regime in which the global morphology may be more determinant. The target is to present a systematic and consistent study of both sizes for the various charge states. The size $n=20$ has been abundantly documented in both experimental and theoretical studies and can be viewed as a test case for the present scheme. Photo-electron detachment experimental data do also exist on silver and gold anions for size 55, together with trapped ion electron diffraction (TIED) data for $\mathrm{Ag}_{55}$ anions and cations. Both indicate an icosahedral type structure for $\mathrm{Ag}_{55}^{+/-}$. In contrast, the most stable structures for $\mathrm{Au}_{55}^{+/-}$are not yet clearly established. Moreover, it is also interesting, beyond the determination of the absolute minimum structure, to provide a picture of the structures and energy distribution of the other low-energy isomers, and to rationalize their structural patterns. Indeed, these low energy isomers may be possibly observed depending on the experiments, and will likely contribute to the aggregate properties at finite temperature. The paper is organized as follows: in section 2, the DFTB method and the global exploration scheme are briefly presented. In section 3, a detailed description of the relevant isomers extracted from the global exploration is presented. In section 4 , we discuss our results in the light of the previously reported structures. Conclusions and perspectives are provided in the last section.

\section{Computational Details}

\subsection{The DFTB and SCC-DFTB Methods}

DFTB $[54,55,56,57,58,59]$ is an approximation of DFT in its orbital formulation proposed by Hohenberg, Kohn and Sham [68, 69]. In the DFTB method: (i) the energy is derived from a Taylor series expansion of the DFT energy around a reference density, (ii) the Kohn-Sham orbitals $\varphi_{i}$ are expanded on 90 a set of minimal atom-centered basis, (iii) The first order expression in this basis 
involves matrix elements of the overlap and Hamiltonian $\left(\hat{H}^{0}\right)$ at the reference density, retaining only one- and two-centers terms, (iv) the zeroth-order terms are gathered in a repulsive term $E^{\text {rep }}$ expressed through pairwise contributions. The two levels of DFTB used in this work are: the zeroth-order DFTB and the Self-Consistent-Charge DFTB with the following expressions for the total energy:

First-order DFTB

$$
E^{\text {DFTB }}=\sum_{\alpha, \beta \neq \alpha}^{\text {atoms }} E_{\alpha \beta}^{\mathrm{rep}}+\sum_{i} n_{i}\left\langle\varphi_{i}\left|\hat{H}^{0}\right| \varphi_{i}\right\rangle
$$

\section{Second-order DFTB, referred to as SCC-DFTB (Self-Consistent-Charge-} DFTB)

$$
E^{\mathrm{SCC}-\mathrm{DFTB}}=E^{\mathrm{DFTB}}+\frac{1}{2} \sum_{\alpha, \beta}^{\text {atoms }} \Gamma_{\alpha \beta} q_{\alpha} q_{\beta}
$$

where $n_{i}$ is the occupation number of molecular orbital $\varphi_{i}$. Concerning the parameterization, $E_{\alpha \beta}^{\text {rep }}$ and the non-diagonal elements of the overlap and Hamiltonian matrices in the atomic basis are tabulated from DFT calculations on atomic dimers and expressed as a function of interatomic distances. The diagonal elements of $\hat{H}^{0}$ are the orbital energies of the isolated atoms. In the second order formulation, which leads to a self consistent scheme, the $q_{\alpha}$ are the Mulliken atomic charges and $\Gamma_{\alpha \beta}$ is a diatomic function derived from Hubbard parameters. The DFTB hamiltonian used[67] is spanned on a valence atomic basis including explicitely $n d,(n+1) s$ and $(n+1) p$ atomic orbitals for silver $(n=4)$ and gold $(n=5)$, thus allowing mixing of $d, s$ and $p$ valence electronic character in the cluster DFTB orbitals. Its parametrization[67] was shown to correctly describe the peculiar character of gold clusters, namely the persistence of planar geometries in gold up to sizes 8-12. The spin-restricted version of DFTB was used for all calculations. 


\subsection{Global Optimization Scheme}

The currently most used global optimization techniques include: basin hopping and derived techniques [70, 71], simulated annealing [72] and the developPTMD steps). From each of the three MD runs at $50 \mathrm{~K}$ (low T), $652 \mathrm{~K}$ (medium $T$ ) and $3000 \mathrm{~K}$ (high $T$ ) of the PTMD process, over a thousand configurations equally spaced in time were selected. They were subsequently locally optimized with the SCC-DFTB conjugated gradient scheme, providing a wealth of stable to (i) ensure a better sampling of the various low-energy regions of the phase space and (ii) obtain minima higher in energy than the global minimum. This 
procedure generated a bunch of low energy isomers for each cluster size, and was repeated separately for neutrals, anions and cations, in order to avoid any bias. All calculations were performed using the deMonNano code [79], in which the PTMD scheme has recently been implemented [80]. The PTMD runs were conducted with the non-SCC first-order version of DFTB, whereas the local relaxations were achieved with the SCC-DFTB scheme. This restriction should not be too drastic, since the charge levels under consideration are low $(\mathrm{q}=0,+1,-$ 1), the systems are metal clusters and the charge fluctuations are supposed to be weak.

\section{Global Optimization Results}

Clusters belonging to the same structural families were gathered on the basis of three criteria: (i) the total energy of the cluster $E^{\mathrm{SCC}-\mathrm{DFTB}}$, (ii) the three principal mass-less inertia moments $\mathrm{I}_{1}, \mathrm{I}_{2}$ and $\mathrm{I}_{3}$, characterizing the overall shape of the cluster (namely the usual inertia moments divided by the atom mass) and (iii) the symmetry group of the cluster [81]. In order to bring to light the structural differences between some clusters, the radial atomic distribution describing the variation of the density of atoms as a function of the distance from the center of mass of the cluster was computed. To do that, the number of atoms found in concentric spheres (with radius increments of $1 \AA$ ) was counted. We also determined the coordination numbers of the atoms, defined as the number of nearest neighbors. To do so, we used a threshold distance between two atoms of $3 \AA$, which is relevant for both silver and gold clusters 170 as their nearest-neighbour distances in the bulk are almost identical, 2.889 and $2.886 \AA$, respectively.

\subsection{Global Exploration of 20-Atom Silver Clusters}

The ten most stable structures identified for $\mathrm{Ag}_{20}^{-, 0,+}$ clusters are represented

in Figure 2. The same compact $C_{3}$ structure is found to be the most stable for 


\begin{tabular}{cccc}
\hline System & $\mathrm{n}(<1 \mathrm{eV})$ & System & $\mathrm{n}(<1 \mathrm{eV})$ \\
\hline $\mathrm{Ag}_{20}^{-}$ & 165 & $\mathrm{Ag}_{55}^{-}$ & 6 \\
$\mathrm{Ag}_{20}$ & 115 & $\mathrm{Ag}_{55}$ & 7 \\
$\mathrm{Ag}_{20}^{+}$ & 122 & $\mathrm{Ag}_{55}^{+}$ & 14 \\
$\mathrm{Au}_{20}^{-}$ & 45 & $\mathrm{Au}_{55}^{-}$ & 36 \\
$\mathrm{Au}_{20}$ & 2 & $\mathrm{Au}_{55}$ & 35 \\
$\mathrm{Au}_{20}^{+}$ & 69 & $\mathrm{Au}_{55}^{+}$ & 37 \\
\hline
\end{tabular}

Table 1: Number of isomers found below $1 \mathrm{eV}$ above the global minimum for silver and gold clusters.

both the neutral and cationic form, whereas the most stable structure for $\mathrm{Ag}_{20}^{-}$ belong to the $\mathrm{C}_{s}$ group. We note that for the three charge states, the second most stable isomer has a very weak structural excitation energy above the global minimum (0.006, 0.119 and $0.081 \mathrm{eV}$ for the anionic, neutral and cationic forms, respectively) and that more than one hundred of different structures were identified with energies lower than $1 \mathrm{eV}$ above the global minimum (see Table 1, note that the numbers given in this Table are indicators of the relative complexities of the respective PES, but cannot be considered as the exact numbers of minima on the different PES since they depend on the tolerance threshold used to distinguish between isomer structures). These structures correspond to compact structures, mostly differing by the distribution of hexagonal and pentagonal cycles at the cluster surface. This explains the low level of symmetry detected for these clusters (Table 2) and that the mean inertia moments only weakly depend on the specific isomers as seen in Figure 1.

\subsection{Global Exploration of 20-Atom Gold Clusters}

The most stable structures found for $\mathrm{Au}_{20}^{-, 0,+}$ are close to the well-known pyramidal $T_{d}$ isomer (Figure 3), possibly presenting Jahn-teller distorsion (see below for the anion case). This pyramidal form is pretty stable as the second most stable isomers lies $0.28,0.69$ and $0.34 \mathrm{eV}$ above for the anion, neutral and cation, respectively. Another difference with silver clusters is the low number of 


\begin{tabular}{|c|c|c|c|c|c|c|}
\hline & Isomer & $\Delta E(\mathrm{eV})$ & $\mathrm{I}_{1}$ & $\mathrm{I}_{2}$ & $\mathrm{I}_{3}$ & Symmetry \\
\hline \multirow[t]{10}{*}{$\mathrm{Ag}_{20}^{-}$} & 1 & 0.000 & 146.6 & 135.6 & 123.7 & $C_{s}$ \\
\hline & 2 & 0.006 & 142.6 & 134.9 & 131.6 & $C_{1}$ \\
\hline & 3 & 0.036 & 151.1 & 139.2 & 120.3 & $C_{1}$ \\
\hline & 4 & 0.040 & 139.7 & 139.7 & 137.8 & $C_{1}$ \\
\hline & 5 & 0.052 & 160.2 & 148.3 & 106.1 & $C_{s}$ \\
\hline & 6 & 0.064 & 139.6 & 138.2 & 126.3 & $C_{s}$ \\
\hline & 7 & 0.075 & 147.6 & 136.2 & 125.8 & $C_{1}$ \\
\hline & 8 & 0.087 & 154.0 & 133.5 & 122.3 & $C_{2 v}$ \\
\hline & 9 & 0.095 & 147.9 & 146.3 & 112.7 & $C_{2 v}$ \\
\hline & 10 & 0.102 & 145.5 & 141.1 & 118.6 & $C_{1}$ \\
\hline \multirow[t]{10}{*}{$\mathrm{Ag}_{20}$} & 1 & 0.000 & 141.7 & 131.8 & 131.8 & $C_{3}$ \\
\hline & 2 & 0.119 & 139.1 & 139.1 & 134.7 & $C_{3}$ \\
\hline & 3 & 0.157 & 140.0 & 135.0 & 125.4 & $C_{s}$ \\
\hline & 4 & 0.186 & 142.2 & 138.3 & 123.1 & $C_{1}$ \\
\hline & 5 & 0.201 & 135.4 & 133.6 & 129.7 & $C_{s}$ \\
\hline & 6 & 0.233 & 143.3 & 133.6 & 127.2 & $C_{1}$ \\
\hline & 7 & 0.238 & 145.7 & 136.6 & 121.7 & $C_{1}$ \\
\hline & 8 & 0.259 & 145.5 & 131.3 & 130.4 & $C_{1}$ \\
\hline & 9 & 0.301 & 143.4 & 141.1 & 124.9 & $C_{2 v}$ \\
\hline & 10 & 0.321 & 140.9 & 138.8 & 119.6 & $C_{1}$ \\
\hline \multirow[t]{10}{*}{$\mathrm{Ag}_{20}^{+}$} & 1 & 0.000 & 142.5 & 129.8 & 129.8 & $C_{3}$ \\
\hline & 2 & 0.081 & 141.0 & 133.3 & 122.7 & $C_{s}$ \\
\hline & 3 & 0.090 & 143.8 & 137.2 & 120.8 & $C_{1}$ \\
\hline & 4 & 0.127 & 135.2 & 132.4 & 127.8 & $C_{2}$ \\
\hline & 5 & 0.134 & 140.5 & 138.8 & 117.3 & $C_{1}$ \\
\hline & 6 & 0.139 & 144.0 & 130.5 & 122.5 & $C_{1}$ \\
\hline & 7 & 0.159 & 145.9 & $\begin{array}{l}131.3 \\
10\end{array}$ & 125.7 & $C_{1}$ \\
\hline & 8 & 0.163 & 147.1 & 129.3 & 129.0 & $C_{1}$ \\
\hline & 9 & 0.170 & 150.4 & 131.9 & 120.1 & $C_{1}$ \\
\hline & 10 & 0.174 & 146.0 & 140.0 & 116.5 & $C_{1}$ \\
\hline
\end{tabular}

Table 2: Energetics and principal mass-less moments of inertia (in $\AA^{2}$ ) of $\mathrm{Ag}_{20}$ clusters. 

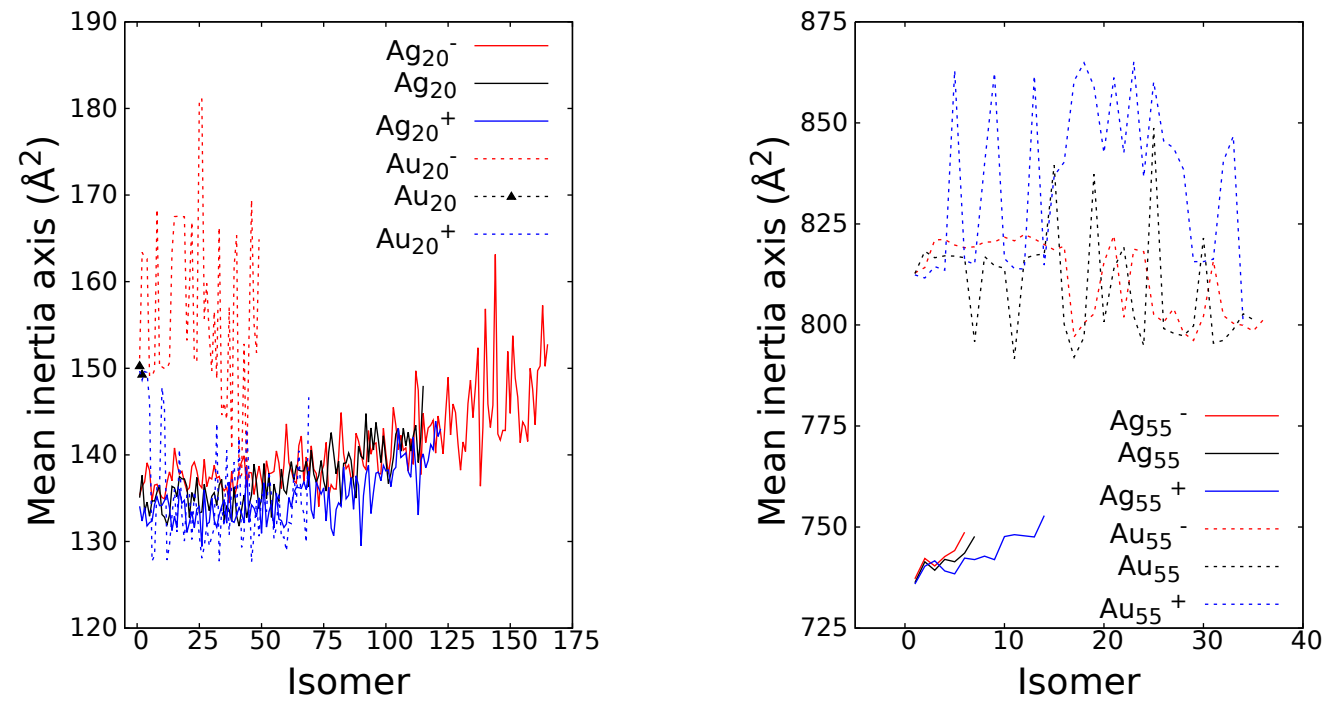

Figure 1: Mean inertia moments for silver and gold clusters of 20 (left) and 55 (right) units. On each plot, only the values of the mean inertia moments corresponding to isomers found below $1 \mathrm{eV}$ above the global minimum are depicted.

structures found below $1 \mathrm{eV}$ (45, 2 and 69 for the anionic, neutral and cationic states respectively, Table 1). For $\mathrm{Au}_{20}$, the second most stable is a structure strongly distorted from the $T_{d}$ pyramid, while third isomer can be seen as a pyramid with one apex atom displaced to the face opposite to its original position. The most stable isomer of $\mathrm{Au}_{20}^{+}$is also a a pyramidal structure with $T_{d}$ symmetry. We have found no significant distorsion (if it exists, it is less than $0.01 \AA$ ). Many of the low energy isomers above the ground state significantly differ from the pyramidal structure. At higher energies, more compact structures are found, which explains that the mean inertia moments significantly decrease and reach values similar to those obtained for silver clusters (Figure 1). The most stable anion is also close to a $T_{d}$ pyramid, however Jahn-Teller deformed towards $D_{2 d}$ (with distance distorsions of the order of $0.03 \AA$ ). The other low energy isomers differ though defects from the pyramid, namely the removal of one atom either from a face-center or an apex, transferred as an adatom on top of a triangle or of two edge atoms. In the second lowest energy isomer, the 

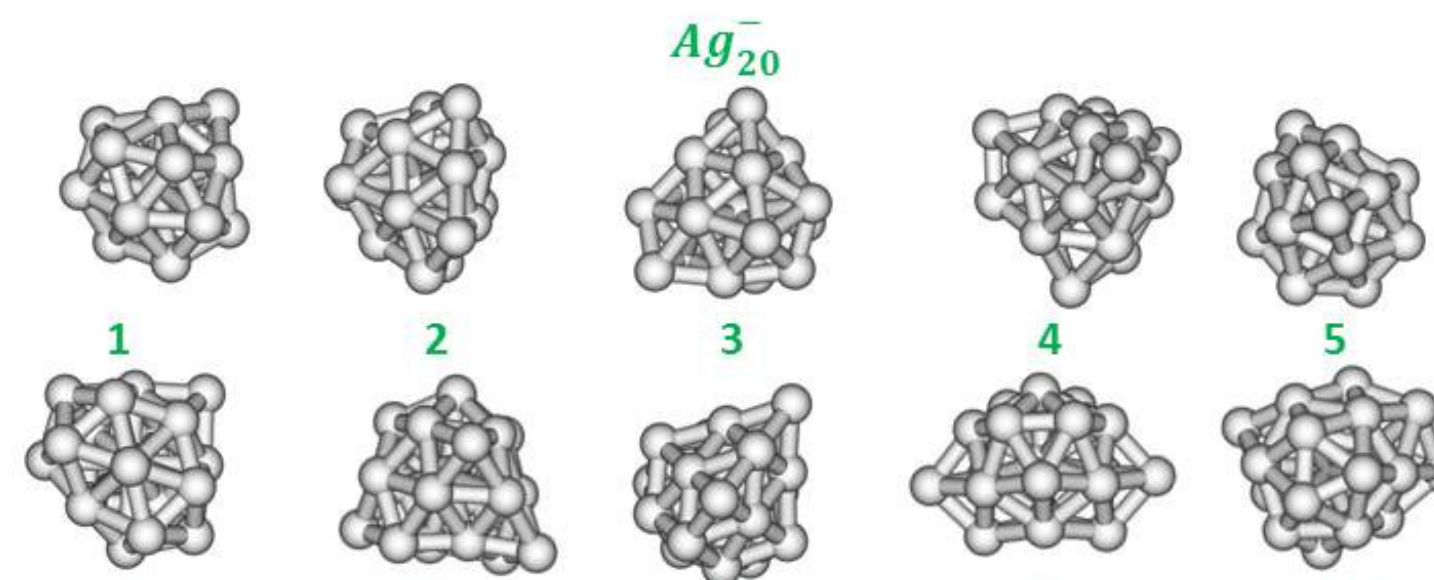

3

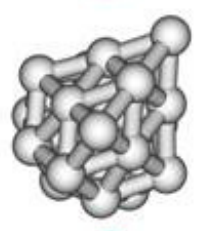

8
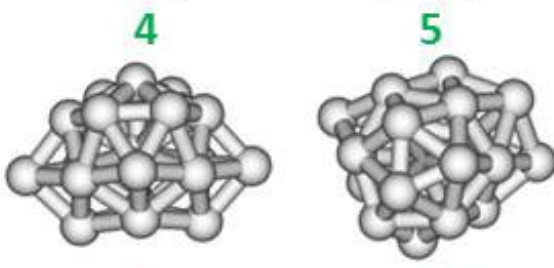

6

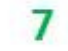

9

10

$\mathrm{Ag}_{20}$
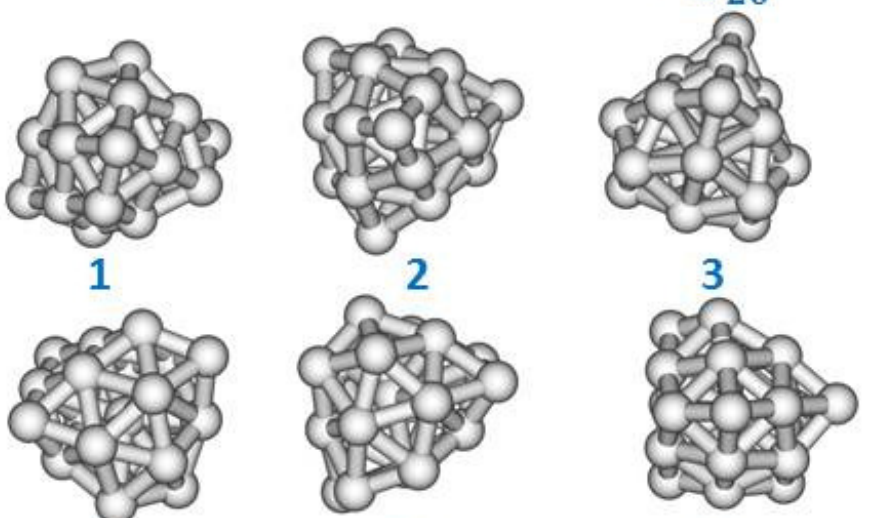

8

7

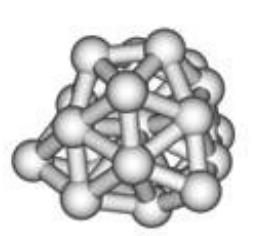

4
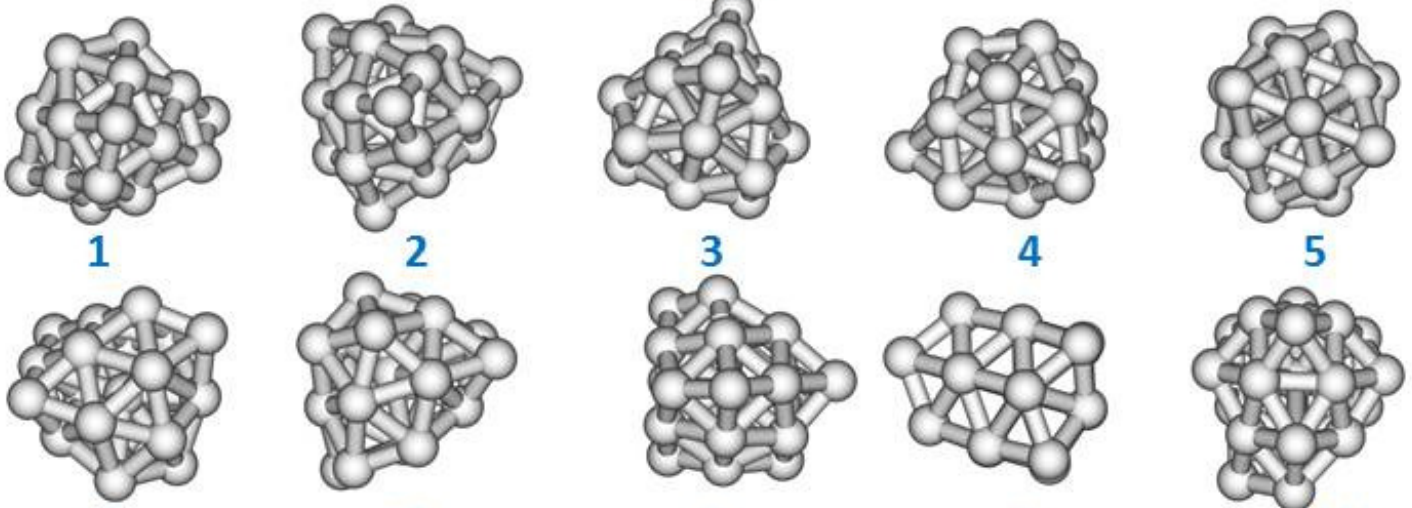

6
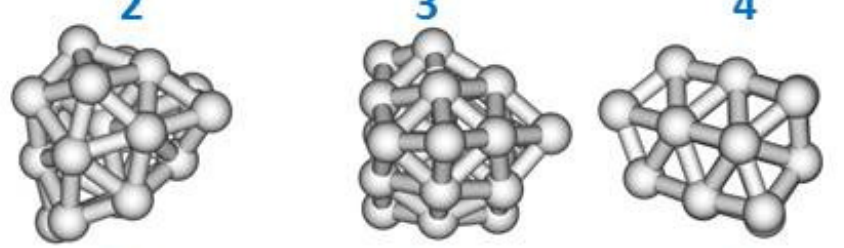

9

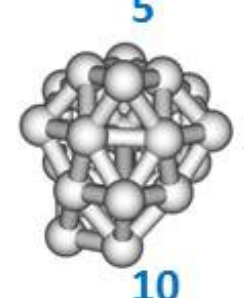

$A g_{20}^{+}$
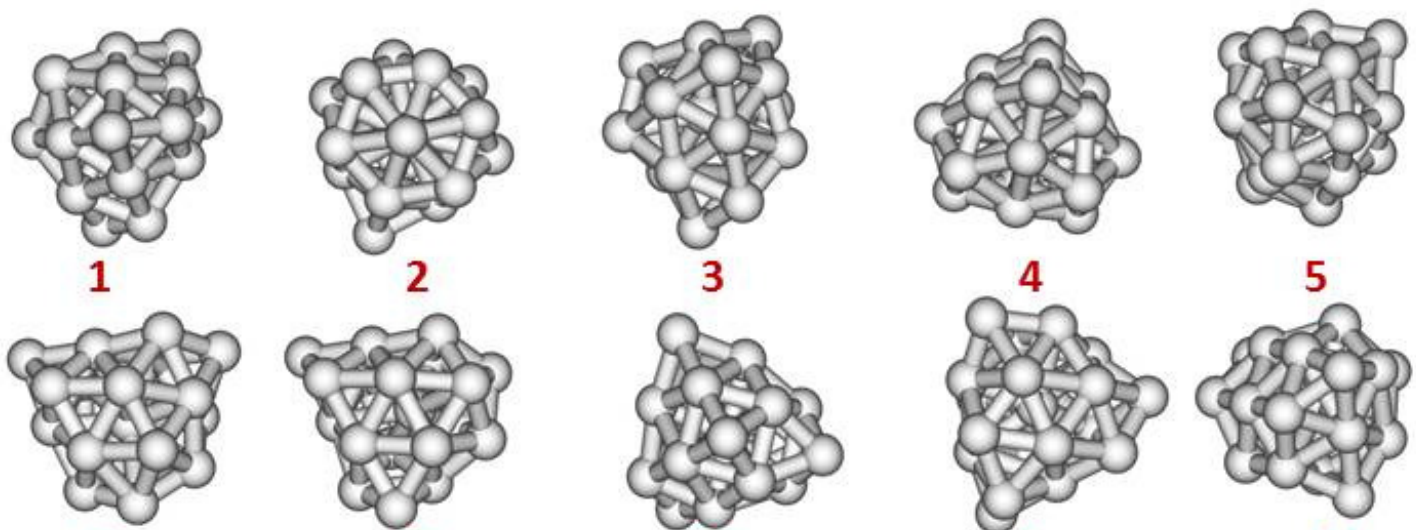

6
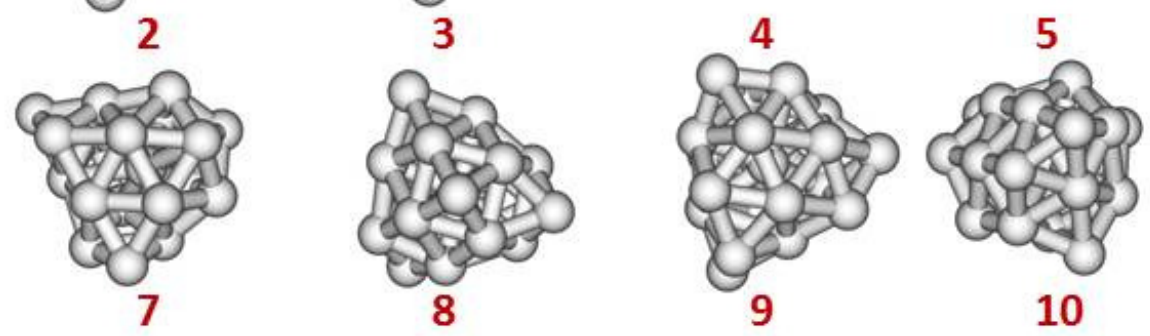

12

Figure 2: 10 lowest-energy minima obtained for $\mathrm{Ag}_{20}^{-}$(green, top), $\mathrm{Ag}_{20}$ (blue, middle) and $\mathrm{Ag}_{20}^{+}$(red, bottom) 
removed and adatom locations correspond to the same face. When an atom is removed from a face center, it leaves a small cavity. In many structures, the removed and adatom positions belong to the same symmetry plane of the initial $T_{d}$ structure, leading to $C_{s}$ symmetries (Table 3 ). Remaining close to $T_{d}$-structures is at the origin of mean inertia moments generally larger than for the cationic forms (Figure 1).

\subsection{Global Exploration of 55-Atom Silver Clusters}

For the three charge states, the most stable structure found for $\mathrm{Ag}_{55}$ is close to an icosahedron. This icosahedron is however slightly distorted into lower symmetry deformations namely $D_{3 d}, D_{2 h}$ and $D_{5 d}$ for the anion, the neutral and the cation respectively. Only 6,7 and 14 local minima were obtained with energies lower than $1 \mathrm{eV}$ above the global minimum for anionic, neutral and cationic forms, respectively (Table 1). All these optimized structures result from defects created in the icosahedron basic form, consisting of the removal of one atom on top of an hexagonal or pentagonal cycle and the addition of an atom either introduced inside a face modifying the surface constraint or added on top of a face triangle or rhombus. If the removed and adatom locations belong to the same symmetry plane, the structure is $C_{s}$ and $C_{1}$ otherwise (Table 4 ). The structures remaining close to the icosahedron, their mean inertia moments also remain close to that of the icosahedron (Figure 1). Furthermore, very few changes are observed on the coordination numbers distributions with respect to that of the icosahedron (Figure 5). Indeed, as can be seen on this figure, the variation fluctuates mainly in the ranges 7-8 and 11-12 neighbors.

\subsection{Global Exploration of 55-Atom Gold Clusters}

The icosahedron form is not competitive for gold clusters with 55 units for which the most stable structure obtained present lower symmetry, quasi $C_{3}$ for the neutral, $C_{3}$ for the cation or no symmetry at all in the anion case, as can be seen in Figure 6 and Table 5 (Note that the neutral shows a very small $C_{1}$ distorsion from the $C_{3}$ structure, with deformations of the order of 0.01 


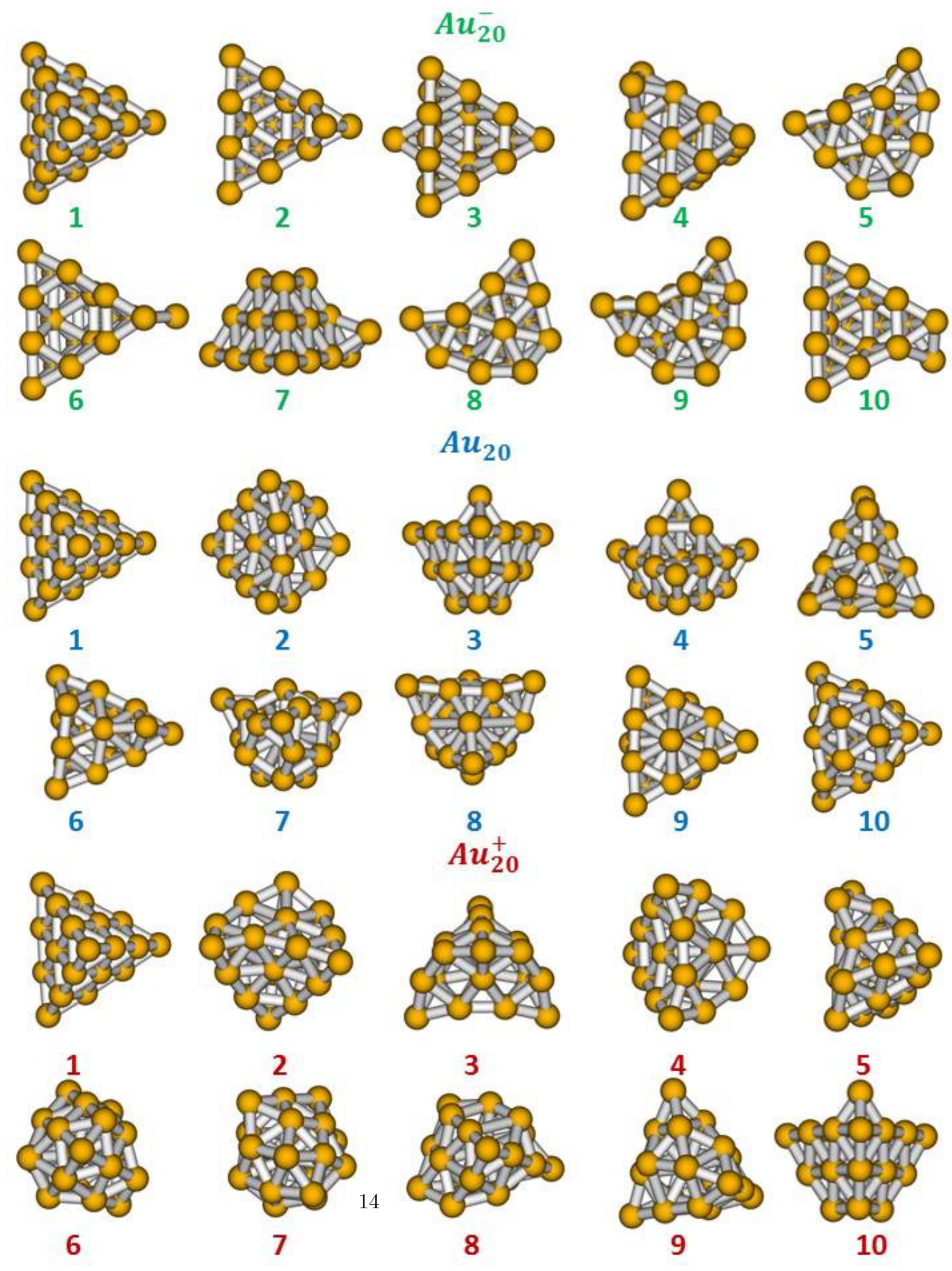

Figure 3: 10 lowest-energy minima obtained for $\mathrm{Au}_{20}^{-}$(green, top), $\mathrm{Au}_{20}$ (blue, middle) and $\mathrm{Au}_{20}^{+}$(red, bottom). 


\begin{tabular}{|c|c|c|c|c|c|c|}
\hline & Isomer & $\Delta E(\mathrm{eV})$ & $\mathrm{I}_{1}$ & $\mathrm{I}_{2}$ & $\mathrm{I}_{3}$ & Symmetry \\
\hline \multirow[t]{10}{*}{$\mathrm{Au}_{20}^{-}$} & 1 & 0.000 & 151.3 & 151.3 & 150.9 & $T_{d}\left(D_{2 d}\right)$ \\
\hline & 2 & 0.277 & 171.2 & 170.4 & 148.6 & $C_{s}$ \\
\hline & 3 & 0.361 & 170.2 & 169.1 & 149.2 & $C_{1}$ \\
\hline & 4 & 0.395 & 164.2 & 149.1 & 134.0 & $C_{s}$ \\
\hline & 5 & 0.413 & 162.9 & 149.5 & 137.0 & $C_{1}$ \\
\hline & 6 & 0.419 & 180.2 & 177.4 & 147.5 & $C_{s}$ \\
\hline & 7 & 0.423 & 173.8 & 149.8 & 126.7 & $C_{1}$ \\
\hline & 8 & 0.433 & 164.4 & 150.0 & 135.5 & $C_{1}$ \\
\hline & 9 & 0.447 & 164.4 & 151.3 & 136.3 & $C_{s}$ \\
\hline & 10 & 0.451 & 172.7 & 171.1 & 146.3 & $C_{1}$ \\
\hline \multirow[t]{10}{*}{$\mathrm{Au}_{20}$} & 1 & 0.000 & 150.3 & 150.3 & 150.3 & $T_{d}$ \\
\hline & 2 & 0.694 & 163.8 & 148.7 & 135.3 & $C_{s}$ \\
\hline & 3 & 1.010 & 157.1 & 141.0 & 138.5 & $C_{s}$ \\
\hline & 4 & 1.022 & 149.2 & 137.6 & 137.6 & $C_{3}$ \\
\hline & 5 & 1.060 & 165.6 & 140.1 & 134.0 & $C_{1}$ \\
\hline & 6 & 1.086 & 164.9 & 139.4 & 134.0 & $C_{1}$ \\
\hline & 7 & 1.183 & 154.4 & 131.1 & 130.8 & $C_{1}$ \\
\hline & 8 & 1.197 & 148.9 & 139.9 & 124.8 & $C_{s}$ \\
\hline & 9 & 1.209 & 157.7 & 130.3 & 129.1 & $C_{1}$ \\
\hline & 10 & 1.213 & 157.4 & 130.5 & 129.2 & $C_{3}$ \\
\hline \multirow[t]{10}{*}{$\mathrm{Au}_{20}^{+}$} & 1 & 0.000 & 150.7 & 149.2 & 149.2 & $T_{d}$ \\
\hline & 2 & 0.340 & 165.0 & 147.2 & 133.6 & $C_{1}$ \\
\hline & 3 & 0.350 & 166.4 & 148.8 & 133.7 & $C_{s}$ \\
\hline & 4 & 0.371 & 165.1 & 149.1 & 134.4 & $C_{s}$ \\
\hline & 5 & 0.416 & 165.8 & 139.3 & 133.1 & $C_{1}$ \\
\hline & 6 & 0.474 & 136.3 & 123.4 & 123.4 & $C_{3}$ \\
\hline & 7 & 0.524 & 144.1 & $\begin{array}{l}128.9 \\
15\end{array}$ & 112.1 & $C_{1}$ \\
\hline & 8 & 0.547 & 154.7 & 131.0 & 124.2 & $C_{1}$ \\
\hline & 9 & 0.551 & 154.2 & 130.5 & 124.4 & $C_{1}$ \\
\hline & 10 & 0.569 & 163.9 & 146.4 & 133.2 & $C_{s}$ \\
\hline
\end{tabular}

Table 3: Energetics and principal mass-less moments of inertia (in $\AA^{2}$ ) of $\mathrm{Ag}_{55}$ clusters. The parenthesis indicates the group corresponding to the Jahn-Teller distorsion 

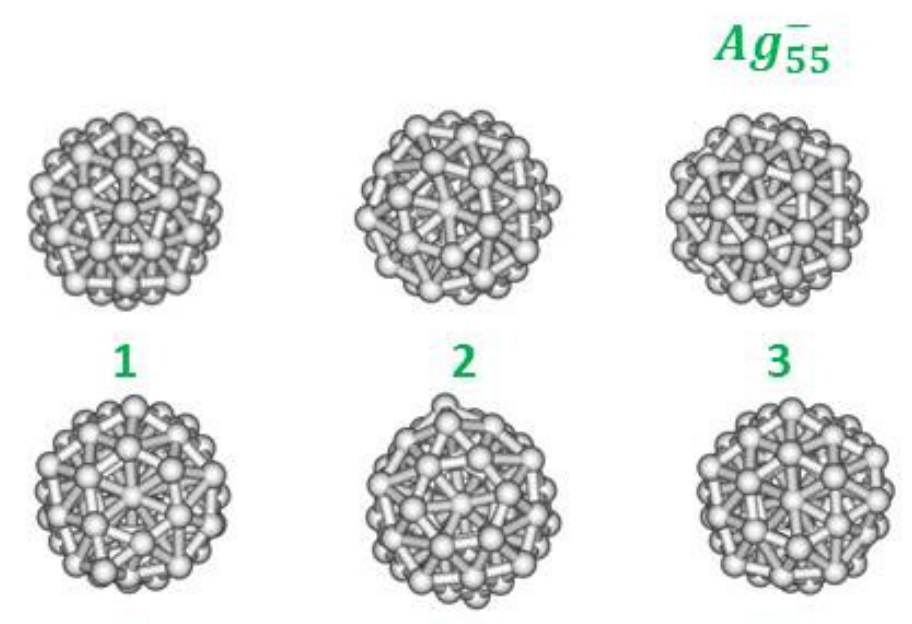

6

7

8
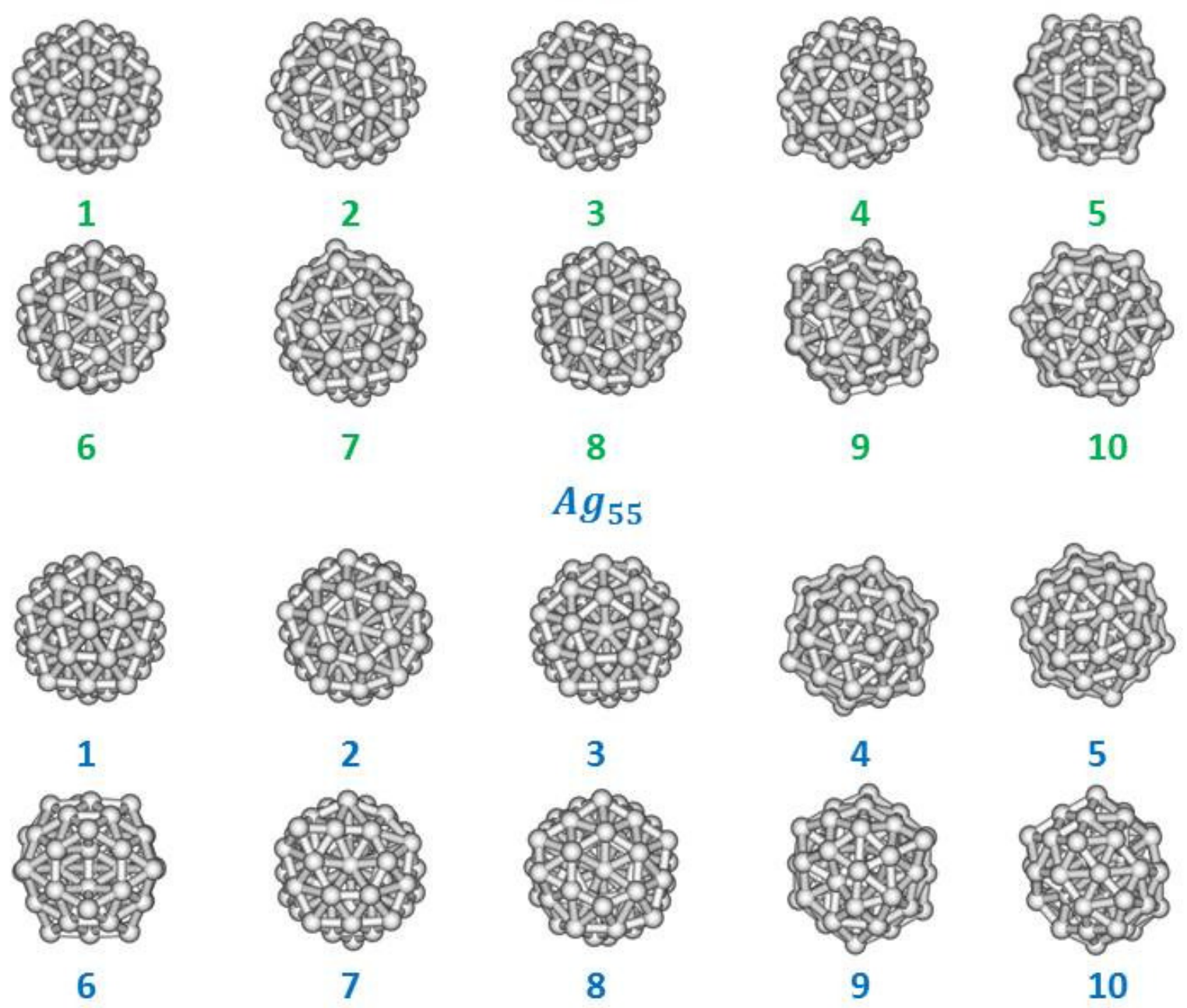

\section{$\mathrm{Ag}_{55}^{+}$}
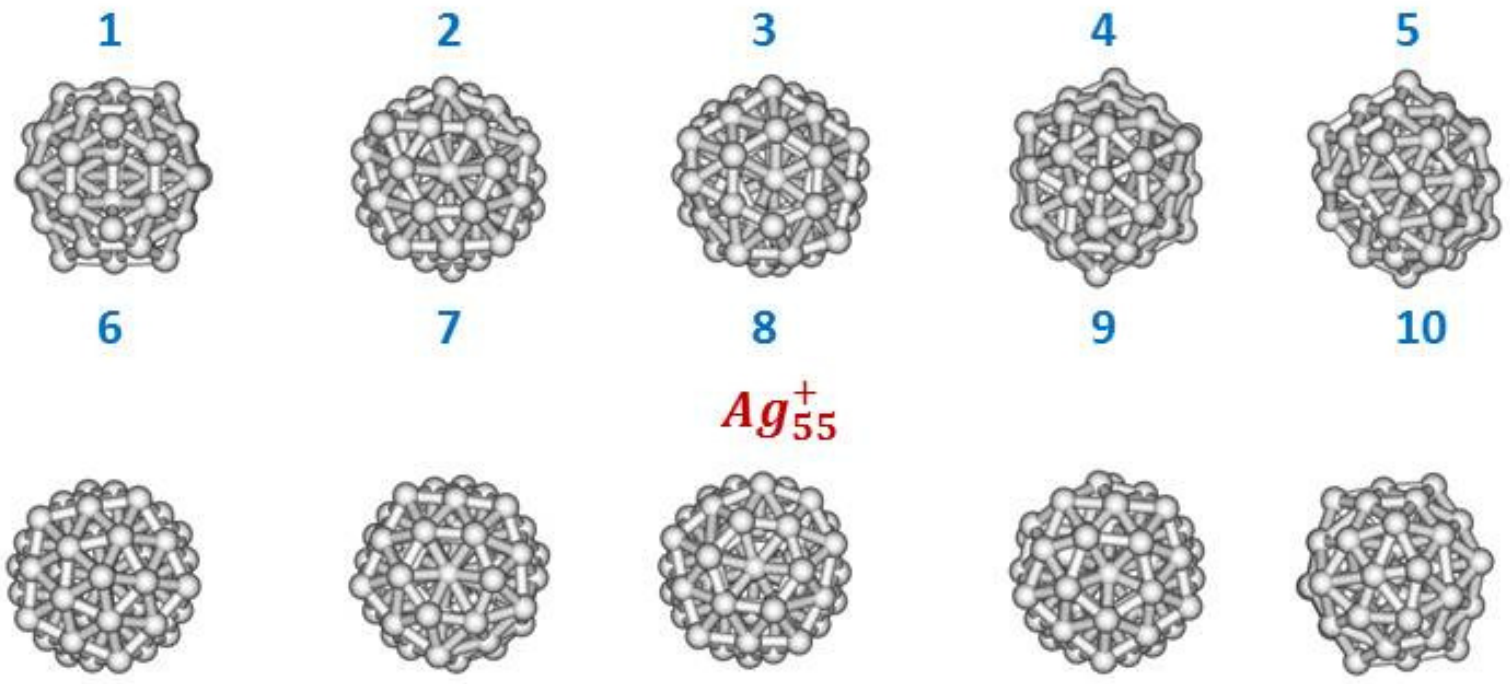

1

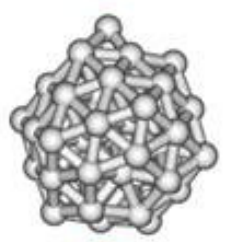

6

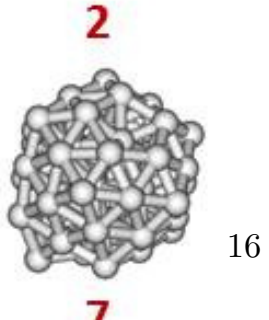

3
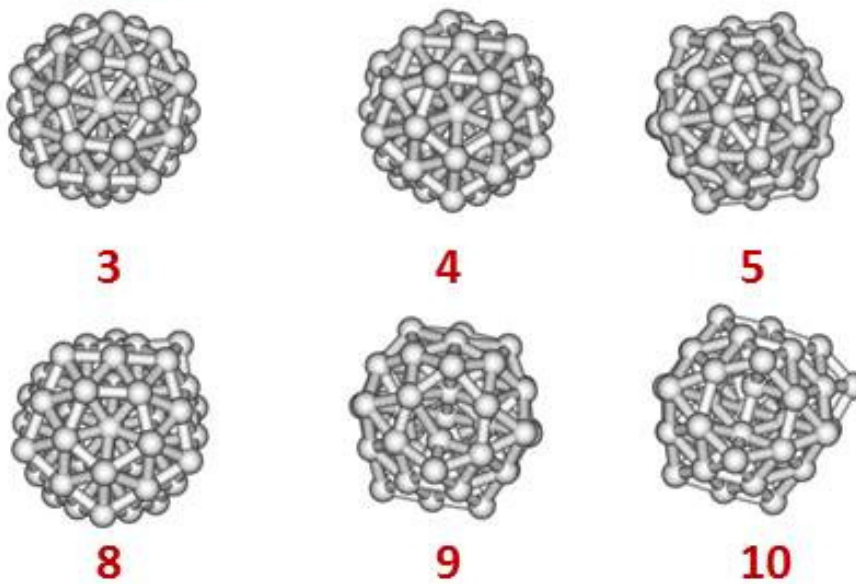

5

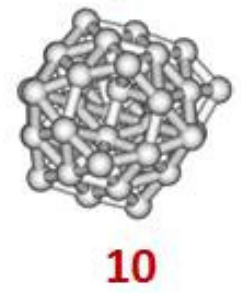

Figure 4: 10 lowest-energy minima obtained for $\mathrm{Ag}_{55}^{-}$(green, top), $\mathrm{Ag}_{55}$ (blue, middle) and $\mathrm{Ag}_{55}^{+}$(red, bottom). 


\begin{tabular}{|c|c|c|c|c|c|c|}
\hline & Isomer & $\Delta E(e V)$ & $\mathrm{I}_{1}$ & $\mathrm{I}_{2}$ & $\mathrm{I}_{3}$ & Symmetry \\
\hline \multirow[t]{10}{*}{$\mathrm{Ag}_{55}^{-}$} & 1 & 0.000 & 743.2 & 734.2 & 734.2 & $I_{h}\left(D_{3 d}\right)$ \\
\hline & 2 & 0.501 & 767.9 & 735.3 & 723.5 & $C_{s}$ \\
\hline & 3 & 0.600 & 767.3 & 734.9 & 718.9 & $C_{s}$ \\
\hline & 4 & 0.740 & 778.2 & 736.8 & 713.1 & $C_{s}$ \\
\hline & 5 & 0.871 & 762.2 & 738.3 & 732.1 & $C_{1}$ \\
\hline & 6 & 0.964 & 786.6 & 741.0 & 718.6 & $C_{1}$ \\
\hline & 7 & 1.026 & 786.3 & 752.1 & 705.0 & $C_{s}$ \\
\hline & 8 & 1.067 & 802.6 & 728.6 & 714.6 & $C_{1}$ \\
\hline & 9 & 1.097 & 785.2 & 747.4 & 714.1 & $C_{1}$ \\
\hline & 10 & 1.136 & 784.0 & 752.0 & 711.3 & $C 1$ \\
\hline \multirow[t]{10}{*}{$\mathrm{Ag}_{55}$} & 1 & 0.000 & 742.0 & 734.2 & 732.5 & $I_{h}\left(D_{2 h}\right)$ \\
\hline & 2 & 0.509 & 768.1 & 732.0 & 724.0 & $C_{s}$ \\
\hline & 3 & 0.599 & 766.0 & 731.1 & 720.8 & $C_{s}$ \\
\hline & 4 & 0.701 & 764.3 & 745.8 & 715.9 & $C_{1}$ \\
\hline & 5 & 0.732 & 760.7 & 739.3 & 724.3 & $C_{s}$ \\
\hline & 6 & 0.843 & 764.9 & 735.9 & 729.9 & $C_{1}$ \\
\hline & 7 & 0.950 & 784.5 & 743.5 & 715.0 & $C_{1}$ \\
\hline & 8 & 1.018 & 801.6 & 728.7 & 712.5 & $C_{1}$ \\
\hline & 9 & 1.048 & 785.9 & 753.6 & 706.8 & $C_{1}$ \\
\hline & 10 & 1.078 & 792.2 & 732.5 & 718.5 & $C_{1}$ \\
\hline \multirow[t]{10}{*}{$\mathrm{Ag}_{55}^{+}$} & 1 & 0.000 & 739.9 & 739.8 & 728.0 & $I_{h}\left(D_{5 d}\right)$ \\
\hline & 2 & 0.509 & 768.1 & 729.1 & 723.7 & $C_{1}$ \\
\hline & 3 & 0.553 & 767.2 & 741.2 & 716.6 & $C_{s}$ \\
\hline & 4 & 0.596 & 766.5 & 727.5 & 723.5 & $C_{s}$ \\
\hline & 5 & 0.632 & 763.0 & 727.3 & 725.0 & $C_{s}$ \\
\hline & 6 & 0.675 & 764.3 & 749.5 & 713.1 & $C_{1}$ \\
\hline & 7 & 0.702 & 766.8 & $\begin{array}{c}740.7 \\
17\end{array}$ & 718.4 & $C_{1}$ \\
\hline & 8 & 0.733 & 780.9 & 743.9 & 703.6 & $C_{s}$ \\
\hline & 9 & 0.783 & 758.9 & 736.6 & 730.2 & $C_{s}$ \\
\hline & 10 & 0.821 & 778.4 & 750.8 & 713.7 & $C_{1}$ \\
\hline
\end{tabular}

Table 4: Energetics and principal mass-less moments of inertia (in $\AA^{2}$ ) of $\mathrm{Ag}_{55}$ clusters. The parenthesis indicates the group corresponding to the Jahn-Teller distorsion 

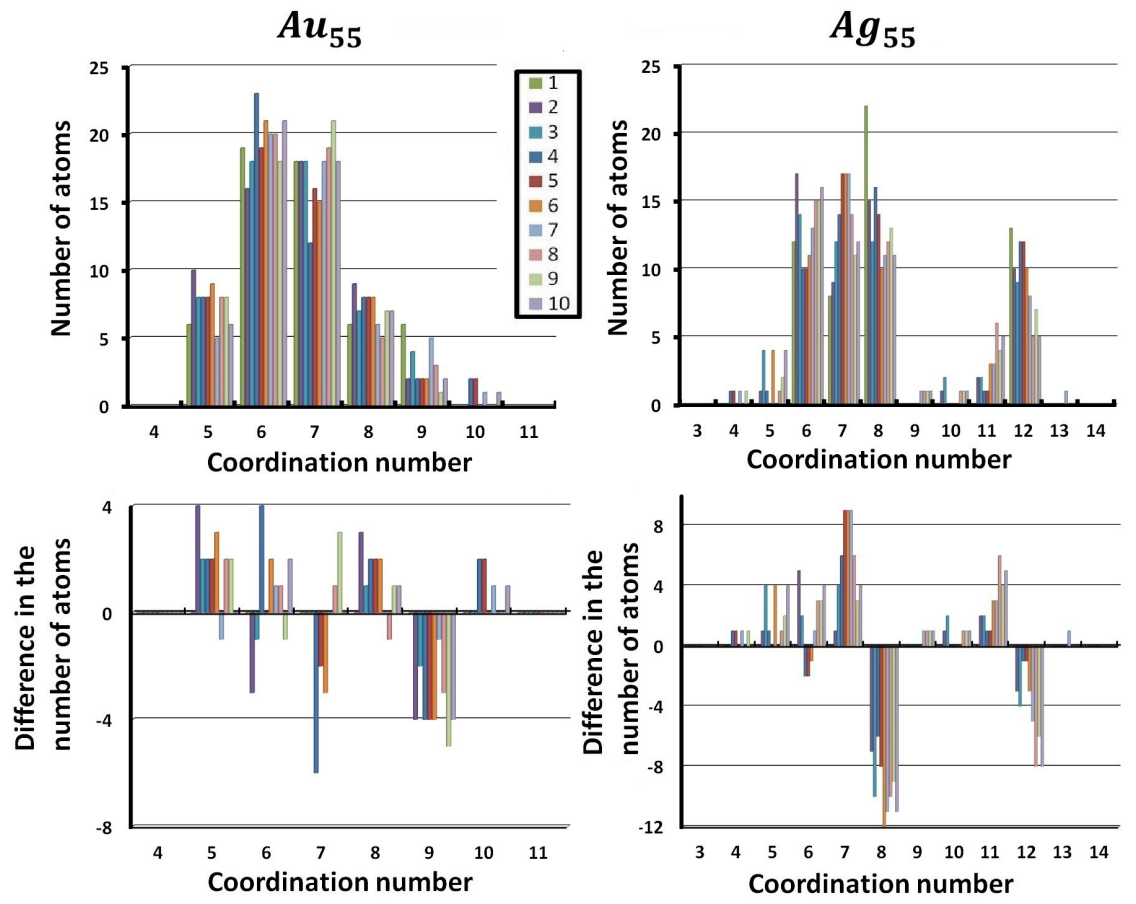

Figure 5: Top: Cumulated distributions of the coordination numbers of the atoms belonging to the top ten $\mathrm{Au}_{55}$ (left) and $\mathrm{Ag}_{55}$ (right) isomers, respectively. Bottom: Differences in the distribution of the coordination numbers with respect to the corresponding global minima. 

above that of the global minimum whatever the considered charge state (Table 1). Several patterns common to all charge states are observed. The first one is the trend to form a cavity inside the cluster as can be seen in Figure 7. The structures are therefore less compact than in the case of $\mathrm{Ag}_{55}$ clusters, presence of these cavities can also be highlighted by comparing the radial atomic distribution of these clusters to the one of the compact icosahedron (Figure 8). The first atomic layer of the cluster is deserted, benefiting to the surface layer. We also recognized the formation of planar patterns at the surface and cavities. This trend can be related to the preference for $2 \mathrm{D}$ structures in small gold clusters, previously observed at the DFT [46] and DFTB [65, 67] levels and attributed to relativistic effects [82]. Finally, we observed that the inside separating plane is sometimes replaced by a central pillar (Figure 7), which in of cationic and neutral forms. Note however that most of the isomers do not present any symmetry. The variations of the coordination number distributions with respect to those of the global minima have an amplitude much smaller than in the case of silver. The most frequently observed variation is a significant reduction in the number of atoms having 9 nearest neighbors. Indeed, in the global minima, 6 atoms correspond to the two bases of the central pillar $(2 \times 3$ atoms) and the loss of the $C_{3}$ symmetry induces a change in the coordination sphere of these atoms. Finally, we also report the presence of square patterns located on the clusters surfaces as can be seen in Figure 6. 

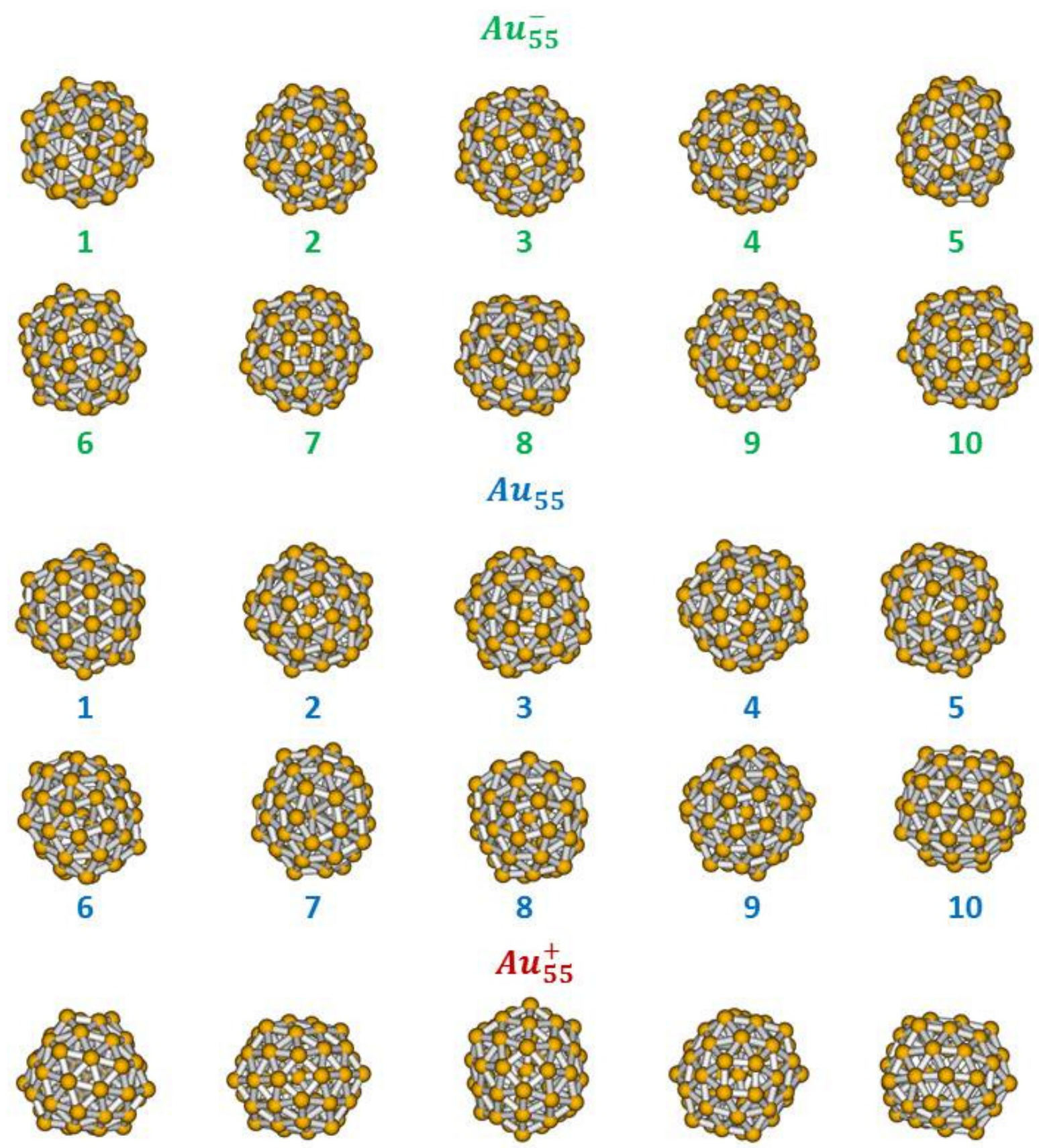

1

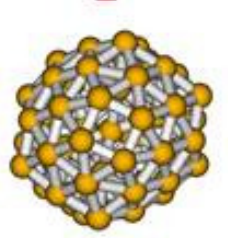

6

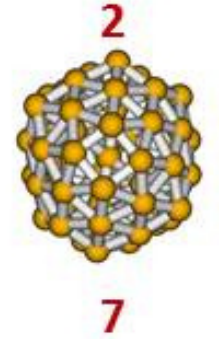

3

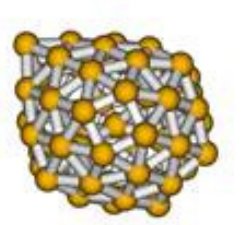

8
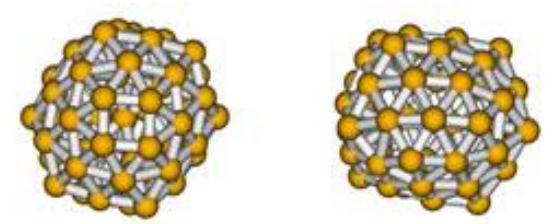

4

5

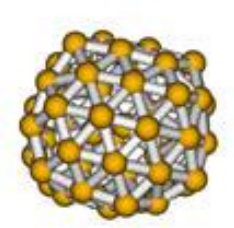

9

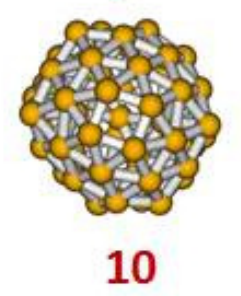

Figure 6: 10 lowest-energy minima obtained for $\mathrm{Au}_{55}^{-}$(green, top), Aus5 (blue, middle) and $\mathrm{Au}_{55}^{+}$(red, bottom). 


\begin{tabular}{|c|c|c|c|c|c|c|}
\hline & Isomer & $\Delta E(\mathrm{eV})$ & $\mathrm{I}_{1}$ & $\mathrm{I}_{2}$ & $\mathrm{I}_{3}$ & Symmetry \\
\hline \multirow[t]{10}{*}{$\mathrm{Au}_{55}^{-}$} & 1 & 0.000 & 874.0 & 788.6 & 776.1 & $C_{1}$ \\
\hline & 2 & 0.027 & 876.4 & 792.0 & 774.2 & $C_{1}$ \\
\hline & 3 & 0.055 & 847.6 & 819.7 & 795.8 & $C_{s}$ \\
\hline & 4 & 0.083 & 845.4 & 820.0 & 798.1 & $C_{s}$ \\
\hline & 5 & 0.111 & 879.8 & 807.0 & 772.6 & $C_{1}$ \\
\hline & 6 & 0.141 & 882.7 & 804.4 & 770.2 & $C_{1}$ \\
\hline & 7 & 0.168 & 867.3 & 805.0 & 785.7 & $C_{1}$ \\
\hline & 8 & 0.196 & 847.4 & 820.4 & 793.7 & $C_{1}$ \\
\hline & 9 & 0.224 & 847.2 & 818.8 & 795.6 & $C_{1}$ \\
\hline & 10 & 0.252 & 876.3 & 811.3 & 777.5 & $C_{1}$ \\
\hline \multirow[t]{10}{*}{$\mathrm{Au}_{55}$} & 1 & 0.000 & 832.4 & 828.2 & 777.5 & $C_{3}\left(C_{1}\right)$ \\
\hline & 2 & 0.053 & 863.0 & 807.9 & 783.9 & $C_{1}$ \\
\hline & 3 & 0.095 & 853.8 & 819.7 & 776.5 & $C_{1}$ \\
\hline & 4 & 0.122 & 854.0 & 818.9 & 778.5 & $C_{1}$ \\
\hline & 5 & 0.153 & 851.5 & 821.7 & 777.9 & $C_{1}$ \\
\hline & 6 & 0.186 & 876.6 & 798.5 & 774.8 & $C_{1}$ \\
\hline & 7 & 0.213 & 851.7 & 771.9 & 764.0 & $C_{1}$ \\
\hline & 8 & 0.244 & 880.8 & 798.3 & 771.7 & $C_{1}$ \\
\hline & 9 & 0.272 & 855.5 & 810.8 & 777.7 & $C_{1}$ \\
\hline & 10 & 0.300 & 840.8 & 821.6 & 779.7 & $C_{1}$ \\
\hline \multirow[t]{10}{*}{$\mathrm{Au}_{55}^{+}$} & 1 & 0.000 & 831.8 & 831.8 & 773.5 & $C_{3}$ \\
\hline & 2 & 0.031 & 832.7 & 829.7 & 772.5 & $C_{3}$ \\
\hline & 3 & 0.064 & 839.0 & 832.4 & 772.0 & $C_{1}$ \\
\hline & 4 & 0.093 & 842.7 & 828.7 & 769.3 & $C_{1}$ \\
\hline & 5 & 0.132 & 911.3 & 867.2 & 810.4 & $C_{2}$ \\
\hline & 6 & 0.167 & 843.3 & 834.9 & 769.7 & $C_{3}$ \\
\hline & 7 & 0.209 & 847.3 & $\begin{array}{l}826.4 \\
21\end{array}$ & 771.3 & $C_{1}$ \\
\hline & 8 & 0.240 & 873.7 & 861.7 & 784.1 & $C_{1}$ \\
\hline & 9 & 0.279 & 898.0 & 866.6 & 822.5 & $C_{1}$ \\
\hline & 10 & 0.307 & 847.2 & 830.6 & 771.5 & $D_{1}$ \\
\hline
\end{tabular}

Table 5: Energetics and principal mass-less moments of inertia (in $\AA^{2}$ ) of $\mathrm{Ag}_{55}$ clusters. 

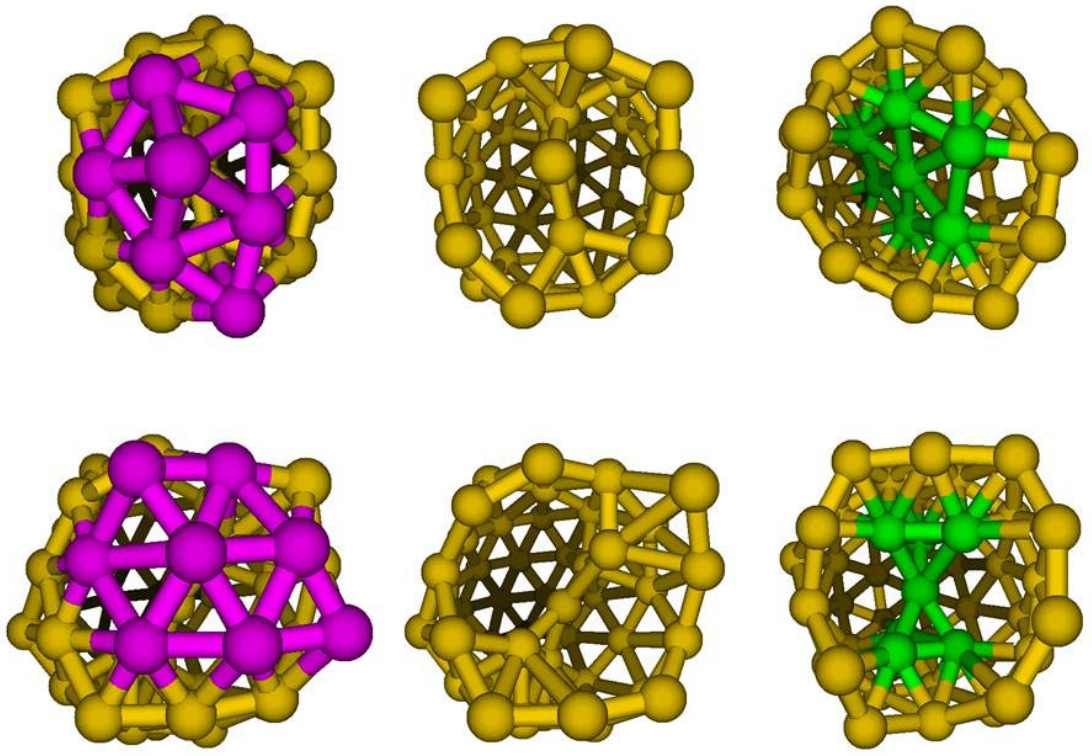

Figure 7: Perspective views of the cavities observed inside isomer number 5 of $\mathrm{Au}_{55}^{-}$(top) and isomer number 5 of $\mathrm{Au}_{55}^{+}$(bottom). The complete structures of the clusters are shown on the left. The violet atoms are cleared to allow for visual observation of the cavities in the middle plots. On the right plots, the clusters are oriented differently to ease the visualization of the atoms belonging to the plane (top, green) or to the pillar (bottom, green). 


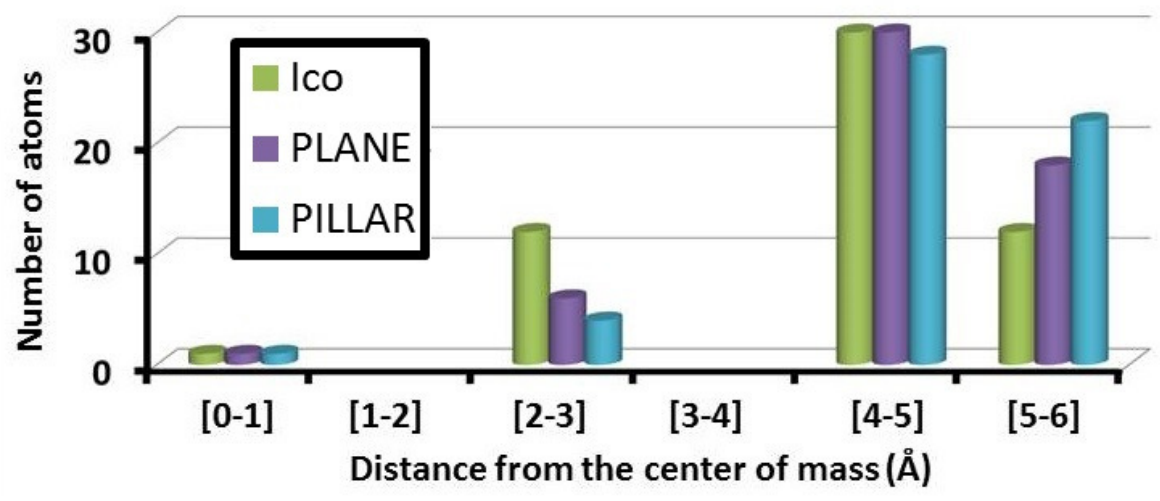

Figure 8: Radial distribution function of a 55-atom icosahedron (green), for isomer number 5 of $\mathrm{Au}_{55}^{-}$(violet) (hollow structure with a separating plane) and for isomer number 5 of $\mathrm{Au}_{55}^{+}$ (blue) (hollow structure with a central pillar).

\section{Discussion}

The structure of 20-atom gold and silver clusters was addressed experimentally via several techniques. The cationic and anionic clusters were addressed in high resolution photo-electron spectroscopy experiments $[35,50,30]$ and from trapped ion electron diffraction (TIED) measurements [52, 48, 53]. A very detailed analysis of the structure of ions (cations and anions) using DFT calculations combined with TIED experimental data for 20-atom metal clusters with various charges was carried out by Letchke and coworkers [53]. A review was given by Schoss et al. [83]. Assignment of the structures in those experiments generally requires an interplay with theory, and a number of $a b$ initio calculations, generally in the DFT framework, have been carried out either independently or in direct combination to support the experiments $[44,35,51,38,53]$.

Neutral $\mathrm{Au}_{20}$ was characterized from IR spectroscopy[39] and assigned a tetrahedral structure with high $T_{d}$ symmetry, while the ions structures were probed in TIED experiments. The present lowest energy DFTB structures for $\mathrm{Au}_{20}$ and its ions are found to be tetrahedral-like $f c c$ type structures. The neutral 20-mer and the cation have exact $T_{d}$ symmetry, while the anion is slightly 
deformed due to a Jahn-Teller distortion. In the case of neutrals, most higher energy isomers retain the $f c c$ character, although some defects appear. In the case of the ions, the SCC-DFTB higher energy isomers display larger structural fluctuations (mixing of $f c c$ and icosahedral patterns), and, even when similar, do not appear in the same energetic ordering as in the neutral case. The present results are in good agreement with the DFT calculations of Letchke and other authors for the lowest-energy structures of $\mathrm{Au}_{20}, \mathrm{Au}_{20}^{+}$and $\mathrm{Au}_{20}^{-}$. Note that the ionic clusters are both characterized at the DFT level by small $D_{2 d}$ distortions of the tetrahedral $\mathrm{T}_{d}$ geometry. As mentionned previously, this is also the case for the anion in the present DFTB calculation, not for the cation. For $\mathrm{Au}_{20}^{-}$, the experimental TIED data [53] show a very good correlation with the lowest energy tetrahedral isomer and the same assignment had been found from photoelectron spectra experiments [35]. For the cationic species, a mixing between the lowest isomer and the two next ones was found to fit best the TIED data.

The situation of $\mathrm{Ag}_{20}$ and its ions is quite different. Most of the low energy structures found with the present SCC-DFTB scheme consist of variations around an icosahedral-like core, completed or displaying defects. In all cases, the tetrahedral structure is much higher in energy $(\Delta E=0.97,1.30$ and 1.04 $\mathrm{eV}$ for the neutral, the cation and the anion, respectively [67]). The SCC-DFTB lowest-energy configurations of $\mathrm{Ag}_{20}$ and $\mathrm{Ag}_{20}^{+}$actually have $C_{3}$ symmetry and display very small geometrical differences as can be inferred from the principal inertia moments. In contrast, the SCC-DFTB symmetry of $\mathrm{Ag}_{20}^{-}$is found to be $C_{s}$. The present results for the neutral are in good agreement with the DFT results of Letchke et al. [53]. They differ in the case of the anion, although the global icosahedron core pattern is the same in both calculations. Let us note that we find ten isomers for $\mathrm{Ag}_{20}$ in a $0.1 \mathrm{eV}$ range and a similar quasidegeneracy is found by Letchke et al. [53]. Moreover, the assignment of TIED data strongly confirmed the presence of icosahedron-core isomers, but hardly allowed for specific isomer discrimination. Let us also note the recent DFT calculations by Dhillon et al. [27] and Chen et al. [28], which, despite the use of the same TPSS functional, find different results for $\mathrm{Ag}_{20}$. Indeed, the lowest 
isomer of Dhillon is based on an icosahedral pattern, while that of Chen et al. displays a tetrahedral structure.

The situation is less documented for 55-atom clusters. Photo-electron spectroscopy results [38] revealed a clear structuration and a high degeneracy of the electronic energy levels in the case of $\mathrm{Ag}_{55}^{-}$, consistent with a high symmetry shape. In contrast, the photo-electron spectrum for gold was found to be much less structured, suggesting a more intricate electronic structure, possibly corresponding to a less ordered cluster morphology, or to a mixing of structures in the experiment. Hakkinen et al. [34, 51, 38] relaxed at the DFT/LDA level selected geometries such as the icosahedron and cuboctahedron structures, or configurations originating from optimal structures generated with Morse, Sutton-Chen, Gupta and Glue potentials. They found the icosahedron to be the lowest-energy 325 configuration in the case of $\mathrm{Ag}_{55}^{-}$while Sutton Chen and Glue structures were the lowest ones for $\mathrm{Au}_{55}^{-}$, the very symmetric cuboctahedral and icosahedral configurations lying at higher energy. The calculated DFT/LDA photo-electron spectra for the lowest-energy isomers of $\mathrm{Au}_{55}^{-}$appeared to be in line with a rather disordered electronic structure, although the authors mentioned that none of them fully matched the experimental spectra, and that other structures should be considered. Schoss et al. [48] provided TIED data for $\mathrm{Ag}_{55}^{+}$and $\mathrm{Ag}_{55}^{-}$, and showed their correspondence with icosahedral structures, slightly distorted in the case of the anion. The present SCC-DFTB investigation also presents very contrasted results for $\mathrm{Ag}_{55}$ and $\mathrm{Au}_{55}$. The lowest energy structure of $\mathrm{Ag}_{55}$, ${ }_{335} \mathrm{Ag}_{55}^{+} \mathrm{Ag}_{55}^{-}$are found to be Jahn-Teller slightly distorted $I_{h}$ icosahedrons. In contrast, $\mathrm{Au}_{55}$ clusters offer a completely different picture. Indeed, in gold, due to the fact that the structures are more disordered, the SCC-DFTB lowestenergy isomers show a strong dependence upon the charge state. Let us mention a recent size-selected scanning transmission electron microscopy investigation of 340 Wang and Palmer [49], who report a better correspondence of the $\mathrm{Au}_{55}$ STEM images with low symmetry structures $v s$ icosahedra or cuboctahedra, among which possibly chiral geometries. They also report possible structures mixing ordered parts with disordered ones. Some of the higher energy isomers reported 
in the present study possess such dual structure, in particular isomer $\mathrm{Au}_{55}(1)$. case for $\mathrm{Au}_{20}(\Delta E=0.694 \mathrm{eV})$ vs $\mathrm{Ag}_{20}(\Delta E=0.119 \mathrm{eV})$. The same trend can be observed for $\operatorname{Ag}_{55}(\Delta E=0.509 \mathrm{eV})$ vs $\operatorname{Au}_{55}\left(\Delta_{E}=0.053 \mathrm{eV}\right)$. The addition or removal of an electron causes a lowering of this structural energy gap and, 


\begin{tabular}{c|c|c}
\hline Structure & DFT/PW91/PAW & DFTB \\
\hline Cuboctahedron & 3.073 & 5.14 \\
Decahedron & 2.429 & 4.91 \\
Icosahedron & $1.587^{*}$ & $4.36^{*}$ \\
Glue & 1.574 & 3.66 \\
Sutton-Chen & 1.110 & 3.33 \\
Morse & $0.394^{*}$ & 3.37 \\
Isomer 1, this work & 0 & 0 \\
\hline
\end{tabular}

Table 6: DFT and DFTB structural excitation energies (eV) for a sample of selected $\mathrm{Au}_{55}$ structures taken from the present work and from ref. [51]. * indicates a significant structural variation during the optimization.

in general, an increase of the density of isomers. This can also be inferred from Table 1 at least for the 20 -atom clusters. It is worth mentioning that in the case of the 20-atom clusters, the present SCC-DFTB isomer gaps are in quite good agreement with the DFT results of Letchke et al. [53].

Finally, Figure 5 shows a clear difference in the cumulative coordination numbers of the ten isomers investigated here for $\mathrm{Ag}_{55}$ and $\mathrm{Au}_{55}$. A bi-modal distance distribution is observed in the case of silver in contrast to gold which is characterized by a much broader distribution. This somewhat quantifies the order difference between 55-atom gold and silver clusters, not only for the minimal energy structures, but also for the next low-lying isomers.

\section{Conclusion}

There are several conclusions and perspectives to the present study: (i) It demonstrates the feasibility of global optimization using DFTB without prescreening involving a classical potential for sizes up to a few tens of atoms. DFTB is in particular able to deal with Jahn-Teller distorsions; (ii) It proves that the DFTB structures obtained are consistent with previous calculations and available experimental assignments for $\mathrm{Au}_{20}, \mathrm{Ag}_{20}$ or $\mathrm{Ag}_{55}$ ions. It is also in 
qualitative agreement with the photo-electron detachment experiments, TIED experiments and previous calculations based on relaxation of pre-selected configurations for $\mathrm{Ag}_{55}^{-}$and $\mathrm{Au}_{55}^{-}$. If the nearly icosahedral character of the structures of $\mathrm{Ag}_{55}$ and its ions seems now to be well grounded, final conclusion in the case of gold will require further investigations due to larger structural disorder. The present DFTB calculations reveal new disordered structures which have not been previously reported, and may be consistent with the experimental findings in the case of $\mathrm{Au}_{55}$. We have validated the stability of the lowest energy $\mathrm{Au}_{55}$ isomer (cavity type), using a DFT+GGA functional. Obviously, this validation should be further credited by means of DFT with high level functionals and by the calculation of the experimentally measured observables. This is however beyond the scope of the present work; (iii) The present investigation opens direct perspectives such as unbiased optimization addressing other interesting sizes (cages) and a range which covers the transition between clusters and nanoparticles, but also multiply charged clusters; (iv) Finally it will be extremely convenient to use DFTB to investigate phase changes and thermodynamical properties of noble metal clusters.

\section{Appendix A. Supplementary material}

Supplementary data associated with this article can be found, in the online version, at XXX . It contains details about DFT computational details, energetics, structural properties and cartesian coordinates of the DFTB isomers.

\section{Acknowledgements}

This work was granted access to the HPC resources of CALMIP (Grants p1303 and p0059) and from IDRIS (Grant i2015087375). It was supported by a CNRS-Inphyniti Grant (ATHENA 2015 project), the CNRS-GDR EMIE and the NEXT grants ANR-10-LABX-0037 in the framework of the Programme des Investissements d'Avenir (CIM3 and EXTAS projects). 


\section{References}

${ }_{420}^{4}$ [1] V. Kasperovich, V. V. Kresin, Ultraviolet photoabsorption spectra of silver and gold nanoclusters, Philos. Mag. B 78 (4) (1998) 385-396.

[2] S. Lecoultre, A. Rydlo, C. Felix, J. Buttet, S. Gilb, W. Harbich, Optical absorption of small copper clusters in neon: $\mathrm{Cu}_{n},(\mathrm{n}=1-9)$, J. Chem. Phys. 134 (7) (2011) 074303.

[3] V. E. Kaydashev, E. Janssens, P. Lievens, Optical absorption spectra of palladium doped gold cluster cations, J. Chem. Phys. 142 (3) (2015) 034310.

[4] B. Anak, M. Bencharif, F. Rabilloud, Time-dependent density functional study of uv-visible absorption spectra of small noble metal clusters $\left(\mathrm{cu}_{n}\right.$, $\left.\operatorname{ag}_{n}, \mathrm{au}_{n}, \mathrm{n}=2-9,20\right)$, RSC Adv. 4 (2014) 13001-13011.

[5] M. Harb, F. Rabilloud, D. Simon, A. Rydlo, S. Lecoultre, F. Conus, V. Rodrigues, C. Felix, Optical absorption of small silver clusters: $\mathrm{Ag}_{n},(\mathrm{n}=4-22)$, J. Chem. Phys. 129 (19) (2008) 194108.

[6] C.-C. Huang, Z. Yang, K.-H. Lee, H.-T. Chang, Synthesis of highly fluorescent gold nanoparticles for sensing mercury(ii), Angew. Chem., Int. Ed. 46 (36) (2007) 6824-6828.

[7] H. Xu, K. S. Suslick, Water-soluble fluorescent silver nanoclusters, Adv. Mater. 22 (10) (2010) 1078-1082.

[8] Z. Wu, R. Jin, On the ligand's role in the fluorescence of gold nanoclusters, Nano Lett. 10 (7) (2010) 2568-2573.

[9] W. Harbich, S. Fedrigo, J. Buttet, The optical absorption spectra of small silver clusters $(n=5-11)$ embedded in argon matrices, Chemical Physics Letters $195 \quad(5) \quad(1992) 613 \quad$ - 617. doi :http://dx .doi.org/10.1016/0009-2614(92)85572-R.

URL http://www.sciencedirect.com/science/article/pii/ 
[10] S. Fedrigo, W. Harbich, J. Buttet, Collective dipole oscillations in small silver clusters embedded in rare-gas matrices, Phys. Rev. B 47 (1993) 1070610715. doi:10.1103/PhysRevB.47.10706.

URL http://link.aps.org/doi/10.1103/PhysRevB.47.10706

[11] Tabarin, T., Antoine, R., Compagnon, I., Broyer, M., Dugourd, P., Mitrić, R., Petersen, J., Bonačić-Koutecký, V., Eur. Phys. J. D (1). doi:10.1140/ epjd/e2007-00118-5.

[12] K. Baishya, J. C. Idrobo, S. Öğüt, M. Yang, K. Jackson, J. Jellinek, Optical absorption spectra of intermediate-size silver clusters from first principles, Phys. Rev. B 78 (2008) 075439. doi:10.1103/PhysRevB.78.075439.

URL http://link.aps.org/doi/10.1103/PhysRevB.78.075439

[13] G.-T. Bae, C. M. Aikens, Tddft and cis studies of optical properties of dimers of silver tetrahedra, The Journal of Physical Chemistry A 116 (31) (2012) 8260-8269. doi:10.1021/jp305330e.

\section{URL http://dx.doi.org/10.1021/jp305330e}

[14] G. M. Koretsky, M. B. Knickelbein, The reactions of silver clusters with ethylene and ethylene oxide: Infrared and photoionization studies of $a g_{n}\left(c_{2} h_{4}\right)_{m}, a g_{n}\left(c_{2} h_{4} o\right)_{m}$ and their deuterated analogs, J. Chem. Phys. 107 (24) (1997) 10555-10566.

[15] M. Valden, X. Lai, D. W. Goodman, Onset of catalytic activity of gold clusters on titania with the appearance of nonmetallic properties, Science 281 (5383) (1998) 1647-1650.

[16] N. Lopez, J. K. Norskov, Catalytic co oxidation by a gold nanoparticle: a density functional study, J. Am. Chem. Soc. 124 (38) (2002) 11262-11263.

[17] L. M. Molina, B. Hammer, Active role of oxide support during co oxidation at au/mgo, Phys. Rev. Lett. 90 (2003) 206102. 
[18] S. Chretien, M. S. Gordon, H. Metiu, Density functional study of the adsorption of propene on silver clusters, $a g_{m}^{q}(m=1-5 ; q=0,+1)$, J. Chem. Phys. 121 (20) (2004) 9925-9930.

[19] S. Klacar, A. Hellman, I. Panas, H. Gronbeck, Oxidation of small silver clusters: a density functional theory study, J. Phys. Chem. C 114 (29) (2010) 12610-12617.

[20] A. H. Larsen, J. Kleis, K. S. Thygesen, J. K. Norskov, K. W. Jacobsen, Electronic Shell Structure and Chemisorption on Gold Nanoparticles, Phys. Rev. B 84 (24) (2011) 245429.

[21] L. D. Socaciu, J. Hagen, J. Le Roux, D. Popolan, T. M. Bernhardt, L. Wöste, Š. Vajda, Strongly cluster size dependent reaction behavior of co with o2 on free silver cluster anions, The Journal of Chemical Physics 120 (5) (2004) 2078-2081.

45 URL http://scitation.aip.org/content/aip/journal/jcp/120/5/ $10.1063 / 1.1644103$

[22] A. Fielicke, P. Gruene, G. Meijer, D. M. Rayner, The adsorption of $\{\mathrm{CO}\}$ on transition metal clusters: A case study of cluster surface chemistry, Surface Science 603 (10-12) (2009) 1427 - 1433, special Issue of Surface Science dedicated to Prof. Dr. Dr. h.c. mult. Gerhard Ertl, Nobel-Laureate in Chemistry 2007. doi:http://dx.doi.org/10.1016/j.susc.2008.09.064.

URL http://www.sciencedirect.com/science/article/pii/ S0039602809000636

[23] R. Fournier, Theoretical Study of the Structure of Silver Clusters, J. Chem. Phys. 115 (5) (2001) 2165-2177.

[24] E. Fernández, J. Soler, I. Garzón, L. Balbás, Trends in the Structure and Bonding of Noble Metal Clusters, Phys. Rev. B 70 (16) (2004) 165403.

[25] M. Pereiro, D. Baldomir, Determination of the lowest-energy structure of $\mathrm{ag}_{8}$ from first-principles calculations, Phys. Rev. A 72 (2005) 045201. 
[34] H. Häkkinen, M. Moseler, U. Landman, Bonding in cu, ag, and au clusters: Relativistic effects, trends, and surprises, Phys. Rev. Lett. 89 (2002) 033401 .

[35] H. Häkkinen, B. Yoon, U. Landman, X. Li, H.-J. Zhai, L.-S. Wang, On

[26] M. Yang, K. A. Jackson, J. Jellinek, First-principles study of intermediate size silver clusters: Shape evolution and its impact on cluster properties, J. Chem. Phys. 125 (14) (2006) 144308.

[27] H. Dhillon, R. Fournier, Geometric Structure of Silver Clusters with and Without Adsorbed Cl and Hg, Comput. Theor. Chem. 1021 (2013) 26-34.

[28] M. Chen, J. E. Dyer, K. Li, D. A. Dixon, Prediction of structures and atomization energies of small silver clusters, $(\mathrm{ag})_{n}, \mathrm{n} ; 100, \mathrm{~J}$. Phys. Chem. A 117 (34) (2013) 8298-8313.

[29] F. Rabilloud, D. Simon, A. Rydlo, S. Lecoultre, F. Conus, V. Rodrigues, Optical absorption of small silver clusters: $\operatorname{Ag}_{n}(\mathrm{n}=4-22)$, J. Chem. Phys.

[30] B. Yoon, P. Koskinen, B. Huber, O. Kostko, B. von Issendorff, H. Häkkinen, M. Moseler, U. Landman, Size-dependent structural evolution and chemical reactivity of gold clusters, ChemPhysChem 8 (1) (2007) 157-161.

[31] X.-B. Li, H.-Y. Wang, X.-D. Yang, Z.-H. Zhu, Y.-J. Tang, Size dependence of the structures and energetic and electronic properties of gold clusters, J. Chem. Phys. 126 (8) (2007) 084505.

[32] A. V. Walker, Structure and energetics of small gold nanoclusters and their positive ions, J. Chem. Phys. 122 (9) (2005) 094310.

[33] H. Häkkinen, U. Landman, Gold clusters $\left(\mathrm{au}_{n}, 2 \leq \mathrm{n} \leq 10\right)$ and their anions, Phys. Rev. B 62 (2000) 2287-2290.

the electronic and atomic structures of small $\mathrm{au}_{n}^{-}(\mathrm{n}=4-14)$ clusters: A 
photoelectron spectroscopy and density-functional study, J. Phys. Chem. A 107 (32) (2003) 6168-6175.

[36] L. Xiao, L. Wang, From planar to three-dimensional structural transition in gold clusters and the spin-orbit coupling effect, Chem. Phys. Lett. 392 (2004) 452-455.

[37] L. Xiao, B. Tollberg, X. Hu, L. Wang, Structural study of gold clusters, J. Chem. Phys. 124 (11) (2006) 114309.

[38] H. Häkkinen, Atomic and electronic structure of gold clusters: Understanding flakes, cages and superatoms from simple concepts, Chem. Soc. Rev. 37 (2008) 1847-1859.

[39] P. Gruene, D. M. Rayner, B. Redlich, A. F. G. van der Meer, J. T. Lyon, G. Meijer, A. Fielicke, Structures of neutral $\mathrm{au}_{7}, \mathrm{au}_{19}$, and $\mathrm{au}_{20}$ clusters in the gas phase, Science 321 (5889) (2008) 674-676.

[40] M. P. Johansson, A. Lechtken, D. Schooss, M. M. Kappes, F. Furche, 2d-3d transition of gold cluster anions resolved, Phys. Rev. A 77 (2008) 053202.

[41] A. Lechtken, C. Neiss, J. Stairs, D. Schooss, Comparative study of the structures of copper, silver, and gold icosamers: Influence of metal type and charge state, J. Chem. Phys. 129 (15) (2008) 154304.

[42] W. Huang, S. Bulusu, R. Pal, X. C. Zeng, L.-S. Wang, Structural transition of gold nanoclusters: From the golden cage to the golden pyramid, ACS Nano 3 (5) (2009) 1225-1230.

[43] R. Pal, L.-M. Wang, W. Huang, L.-S. Wang, X. C. Zeng, Structure evolution of gold cluster anions between the planar and cage structures by isoelectronic substitution: $\mathrm{Au}_{n}^{-}(\mathrm{n}=13-15)$ and $\operatorname{mau}_{n}^{-}(\mathrm{n}=12-14 ; \mathrm{m}=$ ag, cu), J. Chem. Phys. 134 (5) (2011) 054306.

[44] V. Bonačić-Koutecký, J. Burda, R. Mitrić, M. Ge, G. Zampella, P. Fantucci, Density functional study of structural and electronic properties 
of bimetallic silver-gold clusters: Comparison with pure gold and silver clusters, The Journal of Chemical Physics 117 (7) (2002) 3120-3131.

URL http://scitation.aip.org/content/aip/journal/jcp/117/7/ $10.1063 / 1.1492800$

[45] F. Furche, R. Ahlrichs, P. Weis, C. Jacob, S. Gilb, T. Bierweiler, M. M. Kappes, The structures of small gold cluster anions as determined by a combination of ion mobility measurements and density functional calculations, J. Chem. Phys. 117 (15) (2002) 6982-6990.

[46] M. P. Johansson, I. Warnke, A. Le, F. Furche, At what size do neutral gold clusters turn three-dimensional?, J. Phys. Chem. C 118 (50) (2014) 29370-29377.

[47] A. Tanwar, E. Fabiano, E. P. Trevisanutto, L. Chiodo, F. Della Sala, Accurate ionization potential of gold anionic clusters from density functional theory and many-body perturbation theory, Eur. Phys. J. B 86 (4) (2013) 161.

[48] D. Schooss, M. N. Blom, J. H. Parks, B. v. Issendorff, H. Haberland, M. M. Kappes, The structures of ag55+ and ag55-: Trapped ion electron diffraction and density functional theory, Nano Letters 5 (10) (2005) 1972-1977. doi:10.1021/nl0513434.

URL http://dx.doi.org/10.1021/n10513434

[49] Z. W. Wang, R. E. Palmer, Experimental evidence for fluctuating, chiraltype au55 clusters by direct atomic imaging, Nano Letters 12 (11) (2012) 5510-5514. doi:10.1021/nl303429z.

URL http://dx.doi.org/10.1021/n1303429z

[50] J. Li, X. Li, H.-J. Zhai, L.-S. Wang, $\mathrm{Au}_{2} 0$ : A tetrahedral cluster, Science 299 (5608) (2003) 864-867.

[51] H. Häkkinen, M. Moseler, O. Kostko, N. Morgner, M. A. Hoffmann, B. v. Is- 
[52] X. Xing, B. Yoon, U. Landman, J. H. Parks, Structural evolution of au nanoclusters: From planar to cage to tubular motifs, Physical Review B 74 (16) (2006) 165423-.

[53] A. Lechtken, C. Neiss, J. Stairs, D. Schooss, Comparative study of the structures of copper, silver, and gold icosamers: Influence of metal type and charge state, The Journal of Chemical Physics 129 (15) (2008) 154304. URL http://scitation.aip.org/content/aip/journal/jcp/129/15/

[54] D. Porezag, T. Frauenheim, T. Köhler, G. Seifert, R. Kaschner, Construction of tight-binding-like potentials on the basis of density-functional theory: Application to carbon, Phys. Rev. B 51 (1995) 12947-12957.

[55] G. Seifert, D. Porezag, T. Frauenheim, Calculations of molecules, clusters,

[57] T. Frauenheim, G. Seifert, M. Elsterner, Z. Hajnal, G. Jungnickel, D. Porezag, S. Suhai, R. Scholz, A self-consistent charge density-functional based tight-binding method for predictive materials simulations in physics, chemistry and biology, Phys. Status Solidi B 217 (2000) 41-62.

[58] T. Frauenheim, G. Seifert, M. Elstner, T. Niehaus, C. Köhler, M. Amkreutz, M. Sternberg, Z. Hajnal, A. D. Carlo, S. Suhai, Atomistic 
simulations of complex materials: Ground-state and excited-state properties, J. Phys.: Condens. Matter 14 (2002) 3015-3047.

[59] A. Oliveira, G. Seifert, T. Heine, H. Duarte, Density-functional based tightbinding: an approximate dft method, J. Braz. Chem. Soc. 20 (2009) 11931205.

[60] L. F. L. Oliveira, J. Cuny, M. Moriniere, L. Dontot, A. Simon, F. Spiegelman, M. Rapacioli, Phase changes of the water hexamer and octamer in the gas phase and adsorbed on polycyclic aromatic hydrocarbons, Phys. Chem. Chem. Phys. 17 (2015) 17079-17089.

[61] M. Rapacioli, A. Simon, L. Dontot, F. Spiegelman, Extensions of dftb to investigate molecular complexes and clusters, physica status solidi (b) 249 (2) (2012) 245-258. doi:10.1002/pssb. 201100615.

URL http://dx.doi.org/10.1002/pssb. 201100615

[62] T. H. Choi, Simulation of the $\left(\mathrm{h}_{2} \mathrm{O}\right)_{8}$ cluster with the scc-dftb electronic structure method, Chem. Phys. Lett. 543 (2012) 45-49.

[63] L. Dontot, N. Suaud, M. Rapacioli, F. Spiegelman, An extended dftbci model for charge-transfer excited states in cationic molecular clusters: Model studies versus ab initio calculations in small pah clusters, Phys. Chem. Chem. Phys. 18 (2016) 3545-3557.

[64] A. Fihey, C. Hettich, J. Touzeau, F. Maurel, A. Perrier, C. Köhler, B. Aradi, T. Frauenheim, Scc-dftb parameters for simulating hybrid goldthiolates compounds, J. Comput. Chem. 36 (27) (2015) 2075-2087.

[65] P. Koskinen, H. Häkkine, G. Seifert, S. Sanna, T. Frauenheim, M. Moseler, 630 Density-functional based tight-binding study of small gold clusters, New J. Phys. 8 (1) (2006) 9.

[66] B. Szücs, Z. Hajnal, R. Scholz, S. Sanna, T. Frauenheim, Theoretical study of the adsorption of a ptcda monolayer on s-passivated gaas(1 00 ), Appl. Surf. Sci. 234 (1-4) (2004) 173-177. 
[68] P. Hohenberg, W. Kohn, Inhomogeneous electron gas, Phys. Rev. 136 (3B) (1964) B864-B871.

URL http://link.aps.org/doi/10.1103/PhysRev.136.B864

[69] W. Kohn, L. J. Sham, Self-consistent equations including exchange and

[67] L. F. L. Oliveira, N. Tarrat, J. Cuny, J. Morillo, D. Lemoine, F. Spiegelman, M. Rapacioli, Benchmarking density functional based tight-binding for silver and gold materials: From small clusters to bulk, The Journal of Physical Chemistry A 120 (42) (2016) 8469-8483. doi:10.1021/acs. jpca.6b09292.

URL http://dx.doi.org/10.1021/acs.jpca.6b09292 correlation effects, Phys. Rev. 140 (4A) (1965) A1133-A1138.

URL http://link.aps.org/doi/10.1103/PhysRev.140.A1133

[70] Z. Li, H. A. Scheraga, Monte carlo-minimization approach to the multipleminima problem in protein folding, Proceedings of the National Academy of Sciences 84 (19) (1987) 6611-6615.

URL http://www.pnas.org/content/84/19/6611.abstract

[71] D. J. Wales, J. P. K. Doye, Global optimization by basin-hopping and the lowest energy structures of lennard-jones clusters containing up to 110 atoms, The Journal of Physical Chemistry A 101 (28) (1997) 5111-5116. doi:10.1021/jp970984n.

URL http://dx.doi.org/10.1021/jp970984n

[72] S. Kirkpatrick, C. D. Gelatt, M. P. Vecchi, Optimization by simulated annealing, Science 220 (4598) (1983) 671-680.

[73] Y. Sugita, Y. Okamoto, Replica-exchange molecular dynamics method for protein folding, Chem. Phys. Lett. 314 (1-2) (1999) 141-151.

[74] R. H. Swendsen, J.-S. Wang, Replica monte carlo simulation of spin-glasses, Physical Review Letters 57 (21) (1986) 2607-2609.

URL http://link.aps.org/doi/10.1103/PhysRevLett.57.2607 
[75] D. E. Goldberg, Genetic Algorithms in Search, Optimization and Machine Learning, Addison-Wesley Longman Publishing Co., Inc., 1989.

[76] J. Kennedy, R. Eberhart, Particle swarm optimization, Proc. of IEEE int. conf. on neural networks 4 (1995) 1942-1948.

[77] S. Nosé, A unified formulation of the constant temperature molecular dynamics methods, J. Chem. Phys. 81 (1) (1984) 511. doi:10.1063/1. 447334 URL http://scitation.aip.org/content/aip/journal/jcp/81/1/10. $1063 / 1.447334$

[78] W. G. Hoover, Canonical dynamics: Equilibrium phase-space distributions, Phys. Rev. A 31 (3) (1985) 1695-1697.

[79] T. Heine, M. Rapacioli, S. Patchkovskii, J. Cuny, J. Frenzel, A. Koster, P. Calaminici, H. A. Duarte, S. Escalante, R. Flores-Moreno, A. Goursot, J. Reveles, D. Salahub, A. Vela, deMonNano, http://demon-nano.upstlse.fr/, 1st Sept 2016 (2015).

[80] A. F. Oliveira, P. Philipsen, T. Heine, Dftb parameters for the periodic table, part 2: Energies and energy gradients from hydrogen to calcium, J. Chem. Theory Comput. 11 (11) (2015) 5209-5218.

[81] L. Vázquez-Vidal, Molsym: A program on molecular symmetry and group theory, Journal of Chemical Education 73 (4) (1996) 321. doi:10.1021/ ed073p321.

URL http://dx.doi.org/10.1021/ed073p321

[82] P. Pyykko, Relativistic effects in structural chemistry, Chem. Rev. 88 (3) (1988) 563-594.

[83] D. Schooss, P. Weis, O. Hampe, M. M. Kappes, Determining the sizedependent structure of ligand-free gold-cluster ions, Philosophical Transactions of the Royal Society A: Mathematical, Physical and Engineering Sciences 368 (1915) (2010) 1211-1243. 
[84] J. Wang, J. Jellinek, J. Zhao, Z. Chen, R. B. King, P. von RaguéSchleyer, Hollow cages versus space-filling structures for medium-sized gold clusters: The spherical aromaticity of the au50 cage, The Journal of Physical Chemistry A 109 (41) (2005) 9265-9269. doi:10.1021/jp052414q.

[85] J. P. Perdew, J. A. Chevary, S. H. Vosko, K. A. Jackson, M. R. Pederson, D. J. Singh, C. Fiolhais, Atoms, molecules, solids, and surfaces: Applications of the generalized gradient approximation for exchange and correlation, Phys. Rev. B 46 (1992) 6671-6687. doi:10.1103/PhysRevB.46.6671. URL http://link.aps.org/doi/10.1103/PhysRevB.46.6671

[86] P. E. Blöchl, Projector augmented-wave method, Physical Review B 50 (24) (1994) 17953-17979.

URL http://link.aps.org/doi/10.1103/PhysRevB.50.17953

[87] G. Kresse, D. Joubert, From ultrasoft pseudopotentials to the projector augmented-wave method, Physical Review B 59 (3) (1999) 1758-1775.

URL http://link.aps.org/doi/10.1103/PhysRevB.59.1758 